\title{
Activity-induced gene expression and long-range enhancer-promoter contacts in cohesin-deficient neurons
}

Lesly Calderon $^{1,2}$, Felix D Weiss ${ }^{1,2}$, Jonathan A Beagan ${ }^{3 \$}$, Marta S Oliveira ${ }^{1,2}$, Yi-Fang Wang $^{1,2}$, Thomas Carroll ${ }^{1,2}$, Gopuraja Dharmalingam ${ }^{1,2}$, Wanfeng Gong $^{3}$, Kyoko Tossell ${ }^{1,2}$, Vincenzo de Paola ${ }^{2}$, Chad Whilding ${ }^{1,2}$, Mark A. Ungless ${ }^{1,2}$, Amanda G Fisher $^{1,2}$, Jennifer E Phillips-Cremins ${ }^{3,4,5}$, Matthias Merkenschlager ${ }^{1,2}$ *

${ }^{1}$ MRC London Institute of Medical Sciences, Institute of Clinical Sciences, Faculty of Medicine, Imperial College London, Du Cane Road, London W12 0NN, UK

${ }^{2}$ Institute of Clinical Sciences, Faculty of Medicine, Imperial College London, Du Cane Road, London W12 ONN, UK

${ }^{3}$ Department of Bioengineering, University of Pennsylvania, Philadelphia, PA 19104, USA

${ }^{4}$ Epigenetics Program, Perelman School of Medicine, University of Pennsylvania, Philadelphia, PA 19104, USA

${ }^{5}$ Department of Genetics, Perelman School of Medicine, University of Pennsylvania, Philadelphia, PA 19104, USA

$\$$ Equal contribution

Present addresses

IMP, Vienna, Austria (LC)

Institute of Innate Immunity, University of Bonn, Germany (FDW)

Yale University, New Haven, CT, USA (JAB)

Rockefeller University, NY, USA (TC)

Department of Life Sciences, Imperial College London, UK (KT)

Mental Health Innovations, London, UK (MAU)

*Address correspondence to matthias.merkenschlager@lms.mrc.ac.uk 


\begin{abstract}
Cohesin and CTCF are major drivers of 3D genome organization. Even though human mutations underscore the importance of cohesin and CTCF for neurodevelopment, their role in neurons is only just beginning to be addressed. Here we conditionally ablate Rad21 in cortical neurons, revealing a prominent role for cohesin in the expression of genes that facilitate neuronal maturation, homeostasis, and activation. In agreement with recent reports, activity-dependent genes were downregulated at baseline. However, in contrast to current models that attribute impaired activity-dependent gene expression to a role for cohesin and CTCF in anchoring enhancer-promoter contacts, we show that nearly all activity-dependent genes remain inducible in the absence of cohesin. While CTCF-based chromatin loops were substantially weakened, long-range contacts still formed robustly between activitydependent enhancers and their target immediate early gene promoters. We suggest a model where neuronal cohesin facilitates the precise level of activity-dependent gene expression, rather than inducibility per se, and where inducibility of activity-dependent gene expression is linked to cohesin-independent enhancer-promoter contacts. These data expand our understanding of the importance of cohesin-independent enhancer-promoter contacts in regulating gene expression.
\end{abstract}




\section{Introduction}

Human mutations in CTCF and cohesin-related factors result in intellectual disability ${ }^{1-3}$ and are accompanied by defects in neuronal gene expression ${ }^{4}$. In addition to canonical functions in the cell cycle ${ }^{5}$, cohesin cooperates with the sequence-specific DNA binding protein CTCF in the 3-dimensional (3D) organization of the genome. Cohesin forms CTCF-based loops by a process that generates self-interacting domains that are defined by an increased probability of chromatin contacts within the range of cohesin-mediated loop extrusion ${ }^{6-10}$. This organization is thought to contribute to regulated gene expression by facilitating appropriate enhancer-promoter interactions ${ }^{11-14}$ and its disruption can cause human disease $^{15-16}$, including neurodevelopmental disorders ${ }^{17}$.

Here we establish an experimental system to address the role of cohesin in neuronal 3D genome organisation and gene expression, independently of essential cohesin functions in the cell cycle. We used developmentally regulated $N e x^{\mathrm{Cre}}$ expression ${ }^{18,19}$ to inducibly deplete the cohesin subunit RAD21 in immature post-mitotic mouse neurons in vivo. This approach revealed a previously unrecognised role for cohesin in neuronal maturation, and allowed an in depth characterisation of cohesin's role in neuronal gene expression. Acute proteolytic degradation of RAD21 (RAD21-TEV, Ref. ${ }^{4}$ ) corroborated that cohesin is required for the expression genes involved in neuronal maturation, homeostasis, and activation.

Activity-dependent neuronal genes and their associated enhancers are important for neuronal morphology, the formation of synapses and circuits, and ultimately learning and memory ${ }^{20-24}$. Activity-dependent gene expression is accompanied by acetylation of H3K27, recruitment of RNAP2, cohesin, and other chromatin binding proteins ${ }^{22-28}$. 3D contacts between enhancers and promoters increase in response to neuronal activation at a subset of activity-dependent genes ${ }^{25,27,29}$, and activity-dependent gene expression is impaired in the absence of cohesin or CTCF (Refs. ${ }^{26,29}$ ). Current models attribute impaired activitydependent gene expression to a role for cohesin and CTCF in anchoring specific enhancerpromoter contacts at activity-dependent neuronal genes ${ }^{3,25,26,28,29}$. In contrast to this model, we show that nearly all activity-dependent genes remain inducible in the absence of cohesin. At the activity-dependent Fos locus, inducible transcription was associated with enhancer acetylation, eRNA transcription, and activity-dependent contacts between a set of wellcharacterized enhancers and the Fos promoter. Enhancer-promoter contacts that were activity-dependent at the Arc locus in wild-type cells became constitutive in Rad21 NexCre neurons. We suggest a model where neuronal cohesin is important for the precise level of activity-dependent gene expression, rather than inducibility per se, and where inducibility of 
activity-dependent gene expression is linked to enhancer-promoter contacts that form within this framework by convergent mechanisms, which confer at least partial independence of $\operatorname{cohesin}^{30-37}$.

\section{Results}

\section{Conditional deletion of cohesin in immature post-mitotic neurons}

To explore the role of cohesin in post-mitotic neurons, we deleted the essential cohesin subunit RAD21 ( $\operatorname{Rad} 21^{10 x}$, Ref. ${ }^{38}$ ) in immature cortical and hippocampa neurons using $\mathrm{Nex}{ }^{\mathrm{Cre}}$ (Ref. ${ }^{18,19}$ ). Explant cultures of wild-type and Rad21 ${ }^{\text {lox/lox }} \mathrm{Nex}{ }^{\mathrm{Cre}}$ E17.5/18.5 cortex contained $>95 \% \mathrm{MAP}^{+}$neurons, with $<1 \% \mathrm{GFAP}^{+}$astrocytes or IBA $1^{+}$microglia (Fig. 1a). Immunofluorescence staining showed the loss of RAD21 protein specifically in GAD67neurons (Fig. 1b, c). This was expected, as $\mathrm{Nex}^{\mathrm{Cre}}$ is expressed in excitatory but not in inhibitory neurons ${ }^{18,19}$. Consistent with the presence of $\sim 80 \%$ of GAD67 and $\sim 20 \%$ GAD $67^{+}$ neurons in the explant cultures, Rad21 mRNA expression was reduced by $75-80 \%$ overall (Fig. 1d, left). There was a corresponding reduction in RAD21 protein (Fig. 1d, middle). To focus our analysis on cohesin-deficient neurons we combined $\mathrm{Nex}^{\mathrm{Cre}}$-mediated deletion of $\mathrm{Rad} 21$ with $\mathrm{Nex}^{\mathrm{Cre}}$-dependent expression of an epitope-tagged ribosomal subunit (Rp/22-HA RiboTag; Ref. ${ }^{39}$ ). We verified that $\mathrm{Nex}^{\mathrm{Cre}}$-induced RPL22-HA expression was restricted to RAD21-depleted neurons (Supplementary Fig. 1a) and performed high throughput sequencing of Rpl22-HA RiboTag-associated mRNA (RiboTag RNA-seq). Comparison with total RNA-seq showed that $N e x^{\text {Cre }}$ RiboTag RNA-seq captured excitatory neuron-specific transcripts, such as S/c17a7 and Camk2a. Transcripts selectively expressed in astrocytes (Gfap, Aqp4, Mlc1), microglia (Aif1) and inhibitory neurons (Gad1, Gad2, Slc32a1) were depleted from Nex ${ }^{\text {Cre }}$ RiboTag RNA-seq (Supplementary Fig. 1b). RiboTag RNA-seq enabled an accurate estimate of residual Rad21 mRNA, which was $<5 \%$ in $\operatorname{Rad} 21^{\text {lox } / \text { lox }}$ $\mathrm{Nex}{ }^{\mathrm{Cre}}$ cortical neurons (Fig. 1d, right). These data show near-complete loss of Rad21 mRNA and undetectable levels of RAD21 protein in $\mathrm{Nex}^{\mathrm{Cre}}$-expressing Rad21 $1^{\text {loxlox }}$ neurons. Loss of RAD21 abrogates cohesin-based chromatin loops ${ }^{8}$. Accordingly, analysis of chromatin conformation by $5 \mathrm{C}$ showed a substantial reduction of CTCF-based loop strength in Rad21 $1^{\text {lox/lox }}$ Nex ${ }^{\text {Cre }}$ neurons (Fig. 1e). 

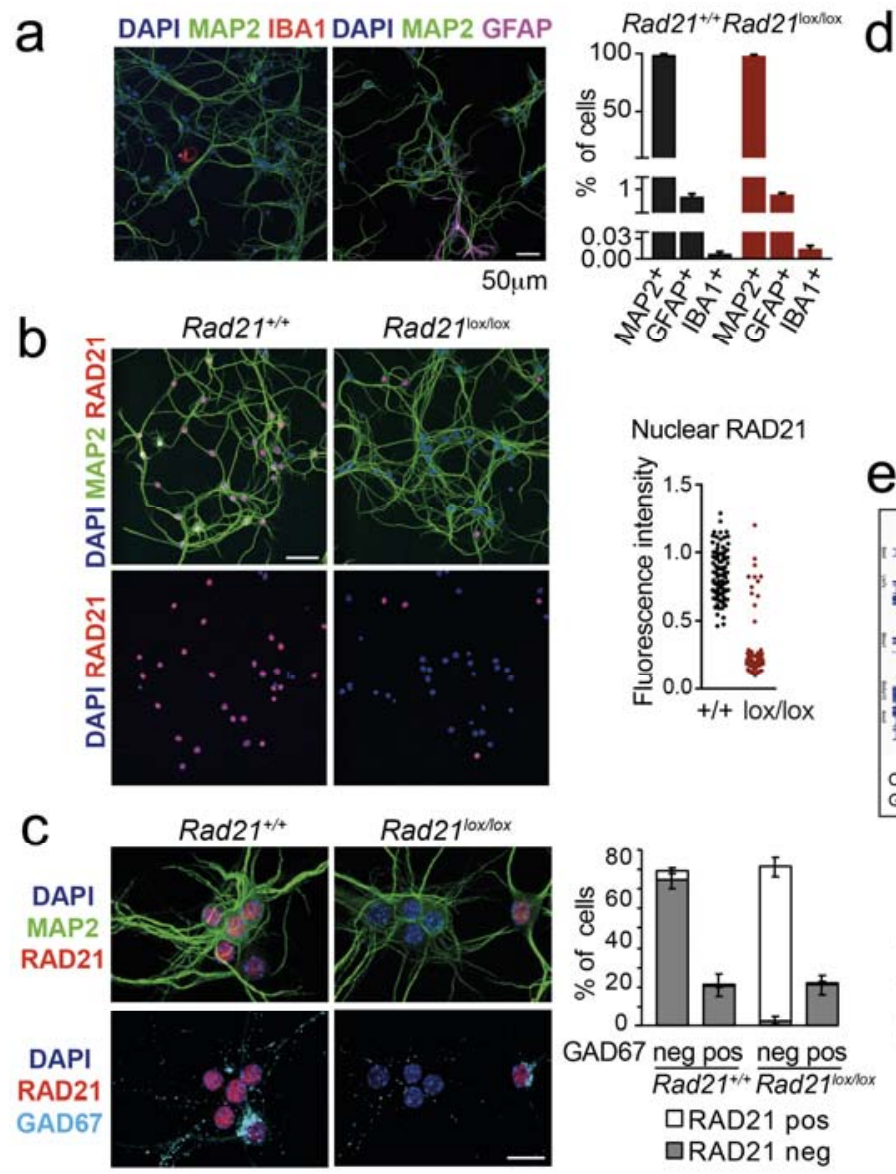

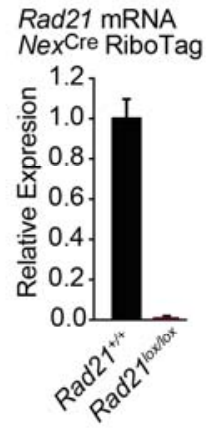

e $\quad \operatorname{Rad} 21^{+/+}$
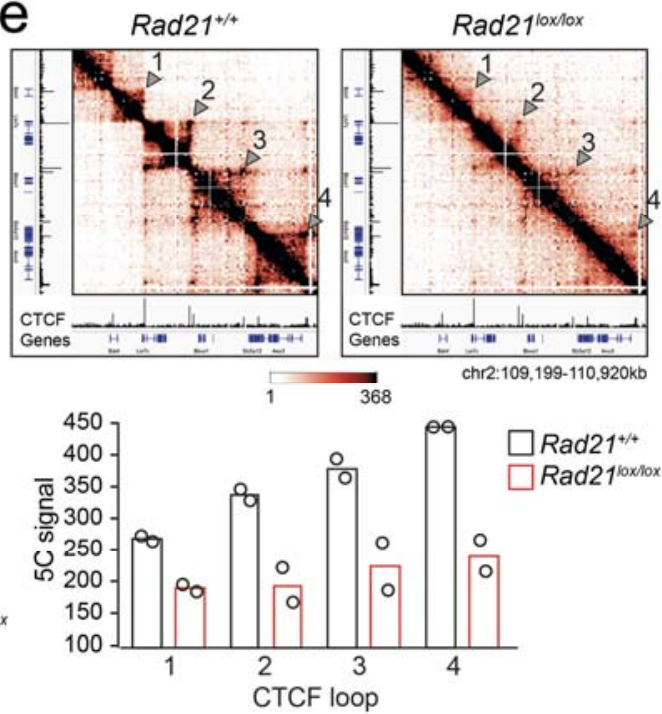

Fig. 1 Conditional cohesin deletion in post-mitotic neurons

a) E17.5-E18.5 cortices were dissociated and plated on poly-D-lysine. After 10d, cultures were stained for pan neuronal (MAP2), astrocyte (GFAP) and microglia (IBA1) markers, and cell type composition was determined by quantitative analysis of immunofluorescence images. Based on $6 \mathrm{Rad} 21^{+/+} \mathrm{Nex}{ }^{\mathrm{Cre}}$ and $8 \mathrm{Rad} 21^{\text {loxllox }} \mathrm{Nex}{ }^{\mathrm{Cre}}$ different samples analysed in 4 independent experiments.

b) Immunofluorescence staining of $\mathrm{Rad}_{2} 1^{+/+} \mathrm{Nex} x^{\mathrm{Cre}}$ and $\mathrm{Rad} 21^{\mathrm{lox} / \mathrm{lox}} \mathrm{Nex}$ Cre neuronal explant cultures for RAD21 and MAP2 (left) and distribution of RAD21 expression by MAP ${ }^{+}$neurons (right). Note the discontinuous distribution of RAD21 expression in Rad21 ${ }^{\text {lox/lox }} \mathrm{Nex}$ Cre neurons. Three independent experiments per genotype. DAPI marks nuclei. Scale bar $=60$ $\mu \mathrm{m}$.

c) Immunofluorescence staining for RAD21, MAP2, and the marker of GABAergic inhibitory neurons, GAD67 (left). Distribution of RAD21 expression in GAD67 ${ }^{+}$and GAD67 neurons (right). Note that the discontinuous distribution of RAD21 expression in Rad21 ${ }^{\text {lox/lox }} \mathrm{Nex}$ Cre neuronal explant cultures is due to $\mathrm{GAD} 67^{+} \mathrm{GABAergic}$ inhibitory neurons. Three independent experiments for Rad $21^{+/+} \mathrm{Nex}$ Cre and 6 independent experiments for Rad $21^{\text {lox lox }}$ $\mathrm{Nex}{ }^{\mathrm{Cre}}$. DAPI marks nuclei. Scale bar $=20 \mu \mathrm{m}$. 
d) Quantitative RT-PCR analysis of Rad21 mRNA expression in Rad21 ${ }^{+/+} \mathrm{Nex}$ Cre and Rad21 $1^{\text {lox/lox }} \mathrm{Nex}$ Cre cortical explant cultures (mean \pm SEM, $\mathrm{n}=18$ ). Hprt and Ubc were used for normalization (left). RAD21 protein expression in $\mathrm{Rad}_{21^{+/+}} \mathrm{Nex}$ Cre and Rad21 ${ }^{\text {loxlox }} \mathrm{Nex} x^{\mathrm{Cre}}$ cortical explant cultures was quantified by fluorescent immunoblots (mean $\pm S E M, n=6$ ) and normalised to LaminB (center). Nex ${ }^{\text {Cre }}$ RiboTag RNA-seq of analysis of Rad21 mRNA expression in $\mathrm{Rad}_{21^{+/+}} \mathrm{Nex}{ }^{\mathrm{Cre}}$ and $\mathrm{Rad} 21^{\text {lox/lox }} \mathrm{Nex}{ }^{\mathrm{Cre}}$ cortical explant cultures (right, 3 independent biological replicates).

e) $5 \mathrm{C}$ heat maps of a $1.72 \mathrm{Mb}$ region on chromosome 2, comparing $\mathrm{Rad}_{21^{+/+}} \mathrm{Nex}$ Cre and Rad2 $1^{\text {lox/lox }} \mathrm{Nex}$ Cre cortical explant cultures. CTCF ChIP-seq (Ref. ${ }^{40}$ ) and mm9 coordinates are shown for reference. Arrowheads mark the position of CTCF-based loops. Results were consistent across two replicates and 3 chromosomal regions Histograms below show the quantification of representative CTCF-based loops (arrowheads) in two independent biological replicates for control and Rad21 $1^{\text {lox/lox }} \mathrm{Nex}$ Cre neurons.

\section{Loss of cohesin from immature post-mitotic neurons perturbs neuronal gene expression}

Using RiboTag RNA-seq to profile gene expression specifically in cohesin-depleted neurons we identified 1028 downregulated and 572 upregulated transcripts in Rad21 ${ }^{\text {loxlox }} \mathrm{Nex}{ }^{\mathrm{Cre}}$ cortical neurons (Fig. 2a, Supplementary Fig. 2), with preferential deregulation of neuronspecific genes ( $P<2.2 \mathrm{e}-16$; http://bioinfo5pilm46.mit.edu:318/neuvenn/). Gene ontology (Fig. 2b) and gene set enrichment analysis (GSEA, Supplementary Fig. 2b) showed that downregulated genes in Rad21 $1^{\text {lox/lox }} \mathrm{Nex}$ Cre neurons were enriched for synaptic transmission, adhesion connectivity, neuronal development and signaling, and for genes linked to human ASD $\left(P=5.10 \mathrm{E}-15\right.$, Supplementary Fig. 2c, Ref. $\left.{ }^{41}\right)$. Neuronal activity-dependent genes ${ }^{21}$ such as Fos, Arc, Egr1, and Bdnf were deregulated 3 times more frequently than nonactivity-dependent, constitutively expressed genes in Rad21 $1^{\text {lox/lox }} \mathrm{Nex}$ Cre neurons (Fig. 2c, $P$ $<1.03 \mathrm{e}-16$, odds ratio $=3.27$ ). Upregulated genes showed no comparable functional enrichment (Fig. 2b).

These data show that immature post-mitotic neurons require cohesin to establish or maintain the correct level of expression of genes that support neuronal maturation, including the growth and guidance of axons, the development of dendrites and spines, and the assembly, function, and plasticity of synapses. We therefore examined the impact of cohesin deletion on the maturation of immature postmitotic neurons. 

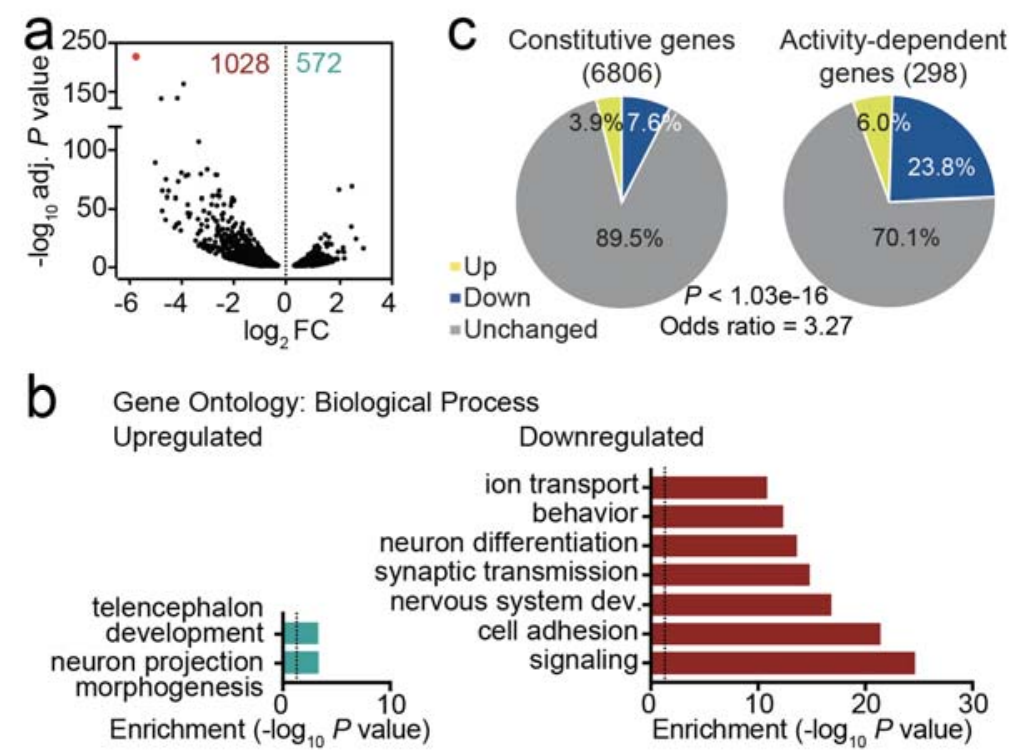

Figure 2. Loss of cohesin from immature post-mitotic neurons perturbs neuronal gene expression

a) Volcano plot representing log2 fold-change (FC) versus significance (-log10 of adjusted $P$ values) of downregulated genes (1028) and upregulated genes (572) in RiboTag RNA-seq

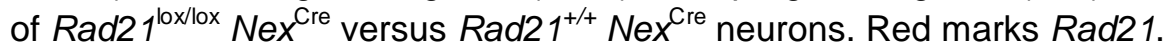

b) Analysis of gene ontology of biological functions of deregulated genes in Rad21 $1^{\text {loxlox }}$ $\mathrm{Nex}{ }^{\mathrm{Cre}}$ neurons. Enrichment is calculated relative to expressed genes.

c) The percentage of constitutive and activity-dependent genes deregulated in Rad210x/lox $N e x^{\text {Cre }}$ neurons in explant culture at baseline as determined by RiboTag RNA-seq. The $P$ value (Fisher Exact Test) and Odds ratio indicate that activity-dependent genes are more frequently deregulated than constitutive genes.

\section{A role for cohesin in the maturation of post-mitotic neurons}

Rad2 $1^{\text {lox/lox }} \mathrm{Nex}$ Cre embryos were found at the expected Mendelian ratios throughout gestation, however postnatal lethality was evident (Supplementary Fig. 3a). Rad21 lox/lox $\mathrm{Nex}{ }^{\mathrm{Cre}}$ cortical neurons did not show increased proliferation (Supplementary Fig. 3b), no upregulation of apoptosis or DNA damage markers (Supplementary Fig. 3b) or stressrelated gene expression (Supplementary Fig. 3c). Brain weight (Supplementary Fig. 3d) and cellularity (Supplementary Fig. 3e) were comparable between Rad $21^{+/+}$and $R a d 21^{\text {lox/lox }}$ $\mathrm{Nex}{ }^{\mathrm{Cre}}$ neocortex. The neuronal transcription factors TBR1, CTIP2 and CUX1 were expressed beyond the boundaries of their expected layers in Rad21 ${ }^{\text {lox/lox }} \mathrm{Nex}$ Cre cortices and 
deeper layers appeared disorganised (Fig. 3a). These findings are consistent with the reported cohesin-dependence of neuronal guidance molecule expression ${ }^{42-44}$ and migration $^{45}$. To assess the impact of cohesin on morphological maturation, we cultured cortical neurons in the presence of wild type glia ${ }^{46}$. Compared to freshly explanted E18.5 neurons (Fig. 3b), neurons acquired considerable morphological complexity after 14 days in explant culture (Fig. 3c). We sparsely labeled neurons with GFP to visualize processes of individual neurons (Fig. 3d) and used Sholl analysis ${ }^{47}$ to quantitate the number of axonal crossings, the length of dendrites, the number of terminal points, the number of branch points and the number of spines in GAD67-negative $\mathrm{Rad}_{21^{+/+}} \mathrm{Nex}{ }^{\mathrm{Cre}}$ and GAD67 negative $\operatorname{Rad}_{2} 1^{\text {lox/lox }} \mathrm{Nex}$ Cre neurons. Cohesin-deficient neurons displayed reduced morphological complexity across scales (Fig. 3c, d), with reduced numbers of axonal branch and terminal points, and reduced numbers of dendritic spines, the location of neuronal synapses (Fig. $3 d)$. Taken together, these data show that the changes in neuronal gene expression that accompany cohesin deficiency have a tangible impact on neuronal morphology, and that cohesin is required for neuronal maturation. 
a
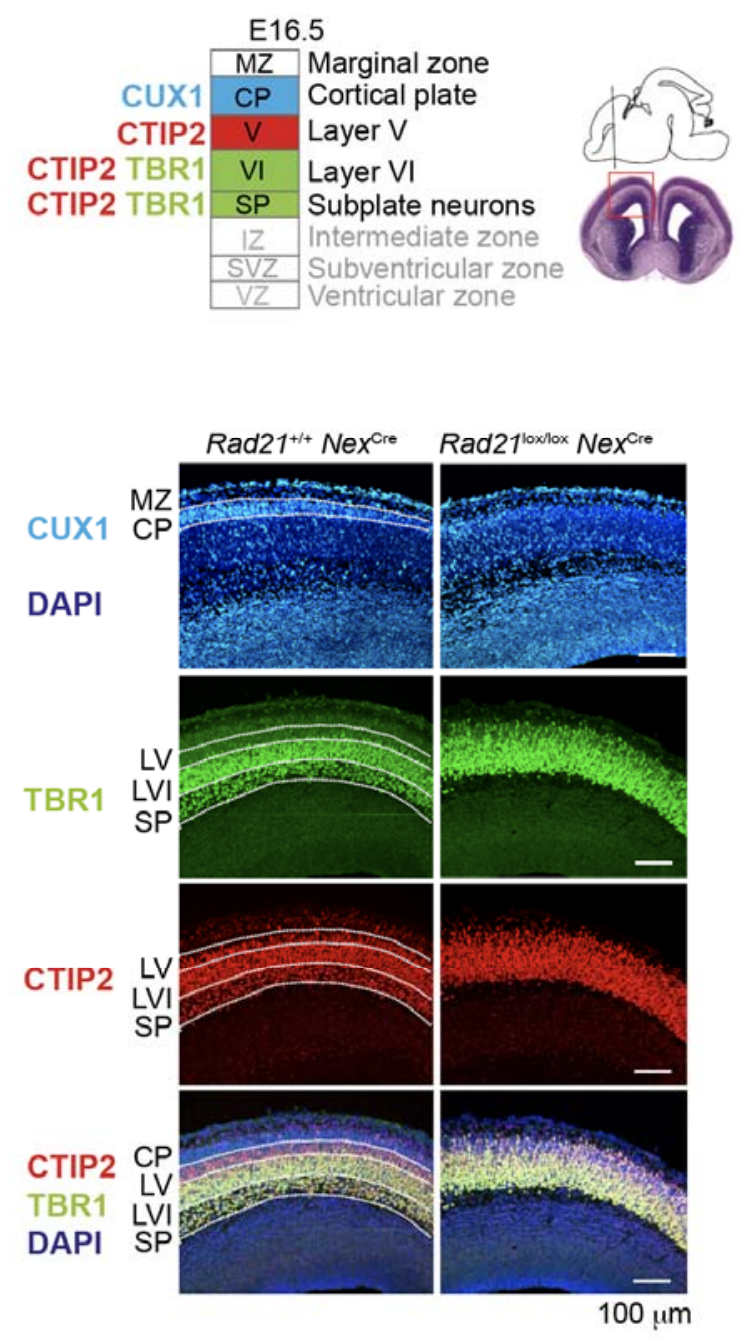

b

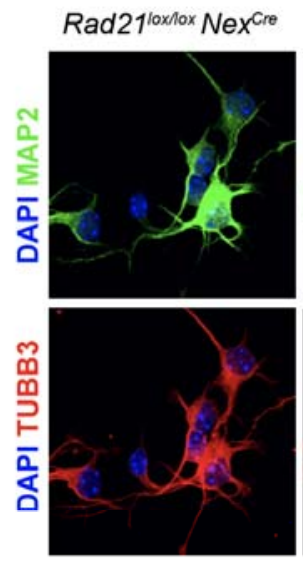

C
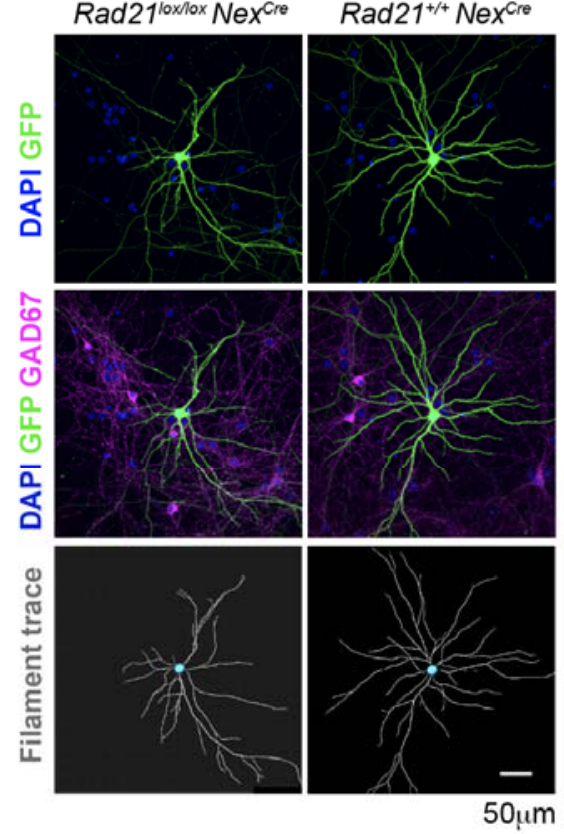

d
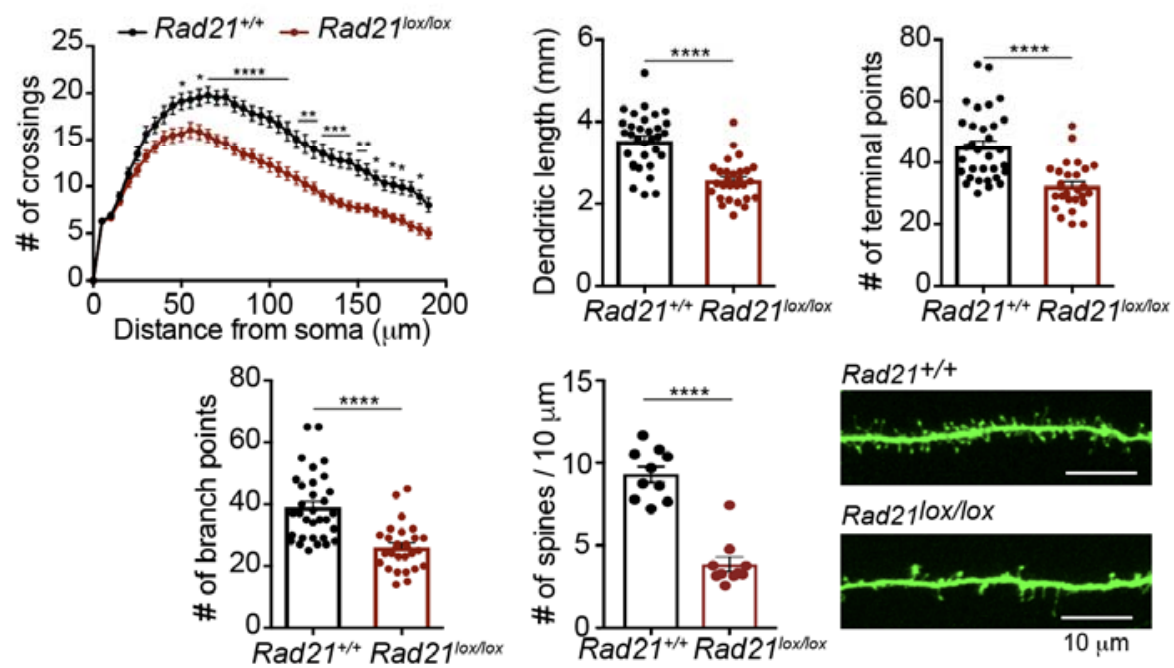

$\operatorname{Rad} 21^{+/+}$

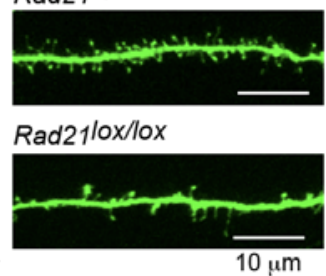

Figure 3. Cohesin contributes to the maturation of post-mitotic neurons 
a) Schema of cortical layers ${ }^{48}$ showing subplate (SP), layer $6(\mathrm{VI})$, layer $5(\mathrm{~V})$, the cortical plate $(\mathrm{CP})$, and the marginal zone (MZ). Immunofluorescence analysis of the neuronal transcription factors CUX1, TBR1, and CTIP2 at E16.5. Representative of 3 biological replicates. Scale bar $=100 \mu \mathrm{m}$.

b) Morphology of E18.5 neurons after $1 \mathrm{~d}$ in explant culture. Immunofluorescence staining for the pan-neuronal marker MAP2, tubulin beta 3 (TUBB3), and DAPI. Scale bar $=20 \mu \mathrm{m}$.

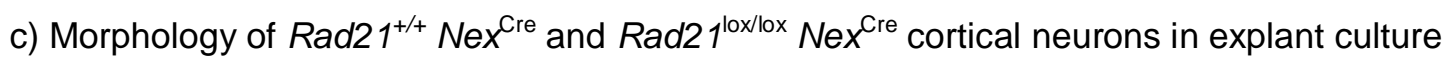
on rat glia ${ }^{46}$. Cultures were sparsely labeled with GFP to visualize individual cells and their processes, and stained for GAD67 to exclude GABAergic neurons. Dendritic traces of GFP ${ }^{+}$ neurons. Scale bar $=50 \mu \mathrm{m}$.

d) Sholl analysis of $\mathrm{Rad}_{2} 1^{+/+} \mathrm{Nex}$ Cre and $\mathrm{Rad} 21^{\text {lox/lox }} \mathrm{Nex}$ Cre cortical neurons in explant cultures shown in $\mathrm{c}$ ). Shown is the number of crossings, dendritic length, terminal points, branch points and spines per $10 \mu \mathrm{m}$. Three independent experiments, $32 \mathrm{Rad} 21^{\text {loxlox }} \mathrm{Nex} \mathrm{Cre}^{\mathrm{Cre}}$ and $28 \mathrm{Rad}_{21^{+/+}} \mathrm{Nex}{ }^{\mathrm{Cre}}$ neurons except for the number of spines (two independent experiments, $10 \mathrm{Rad} 21^{\mathrm{lox} / \mathrm{lox}} \mathrm{Nex} \mathrm{Cre}^{\mathrm{Cre}}$ and $10 \mathrm{Rad} 21^{+/+} \mathrm{Nex}{ }^{\mathrm{Cre}}$ neurons). ${ }^{*}$ adj. $P<0.05,{ }^{* *}$ adj. $P$ $<0.01,{ }^{* * *}$ adj. $P<0.001,{ }^{* * *}$ adj. $P<0.0001$. Scale bar $=10 \mu \mathrm{m}$.

\section{Activity-dependent gene expression is sensitive to acute depletion of cohesin}

Neuronal maturation and activity-dependent gene expression are closely connected: The expression of activity-dependent genes promotes neuronal maturation, morphological complexity, synapse formation, and connectivity. In turn, neuronal maturation, morphological complexity, synapse formation and connectivity facilitate the expression of activitydependent genes ${ }^{20-24}$. To address whether the downregulation of activity-dependent genes observed in Rad21 $1^{\text {lox/lox }} \mathrm{Nex}$ Cre neurons was a cause or a consequence of impaired maturation we examined gene expression changes $24 \mathrm{~h}$ after acute proteolytic degradation of RAD21-TEV depletion in post-mitotic neurons ${ }^{4}$. We found remarkable overlap between acute degradation of RAD21-TEV and genetic cohesin depletion in Rad2 ${ }^{\text {loxlox }} \mathrm{Nex}{ }^{\mathrm{Cre}}$ neurons $(P<2.22 \mathrm{e}-16$, odds ratio $=8.24$ for all deregulated genes, odds ratio $=23.81$ for downregulated genes; Fig. 4a). As illustrated by the key GO term groups related to synapse, adhesion and neuronal/nervous system development, the great majority of genes that were significantly deregulated in either cohesin depletion system showed the same trend in regulation in the other (Synapse: $P<2.22 \mathrm{e}-16$, odds ratio $=11.26, R_{S}=0.62$; Adhesion: $P<$ $2.22 \mathrm{e}-16$, odds ratio $=15.21, R_{S}=0.6$; Neuronal and nervous system development: $P<$ $2.22 \mathrm{e}-16$, odds ratio $=9.92, R_{S}=0.58$; Fig. $4 b$ ). Activity-dependent genes were enriched among deregulated genes in response to acute RAD21-TEV cleavage $(P<2.22 \mathrm{e}-16$, Odds Ratio $=6.48$ ), and were preferentially downregulated (Fig. 4c). We conclude that activity- 
dependent genes and genes that facilitate neuronal maturation and homeostasis are affected by the acute depletion of cohesin.
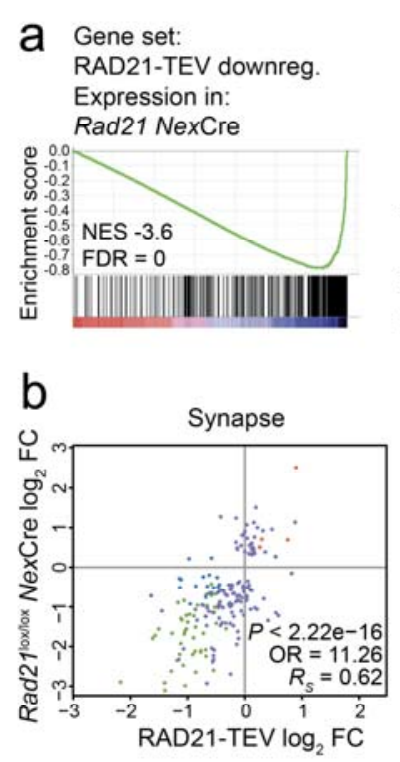

C
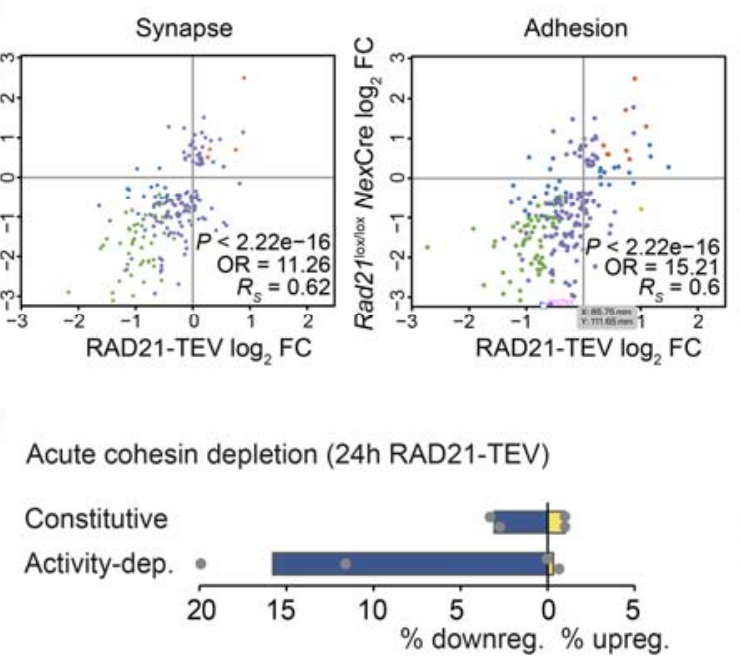

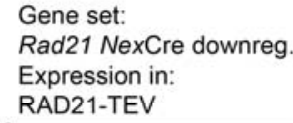

Gene set:

Rad21 NexCre downreg.

Expression in: RAD21-TEV

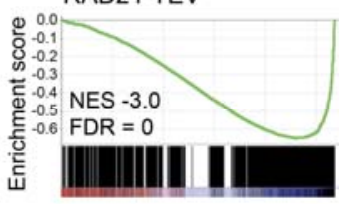

NES: Norm. enrichment score

FDR: False discovery rate

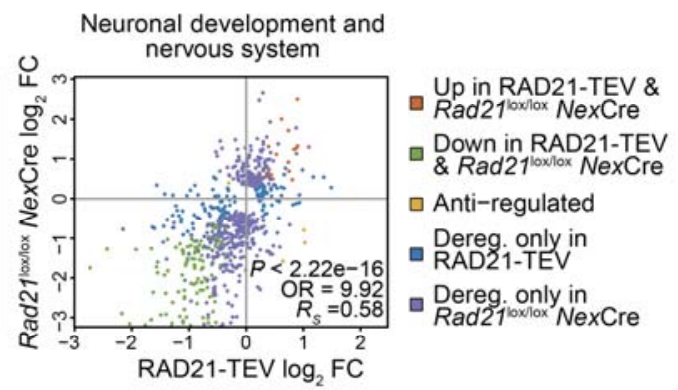

Exp. $1: P=5.89 \mathrm{e}-6, \mathrm{OR}=2.57$

Exp. 2: $P<2.22 \mathrm{e}-16, \mathrm{OR}=6.48$

Figure 4. Activity-dependent gene expression is sensitive to acute cohesin depletion

a) GSEA of the gene set downregulated (DEseq2, adj. $P<0.05$ ) in RAD21-TEV neurons in $\operatorname{Rad} 21^{\text {lox/lox }} \mathrm{Nex} x^{\mathrm{Cre}}$ neurons (left) and GSEA of genes downregulated in Rad2 ${ }^{\text {lox/lox }} \mathrm{Nex}{ }^{\mathrm{Cre}}$ neurons (DEseq2, adj. $P<0.05$ ) in RAD21-TEV neurons.

b) Scatter plots of gene expression within aggregate GO terms, comparing RAD21-TEV with Rad2 $1^{\text {lox/lox }} \mathrm{Nex}{ }^{\text {Cre }}$ neurons. Genes that were found deregulated in at least one of the genotypes are shown. $P$-values and odds ratios refer to the probability of finding the observed patterns of co-regulation by chance. $R_{S}$ : Spearman's rank coefficient.

c) Deregulation of constitutive and activity-dependent genes $24 \mathrm{~h}$ after acute cohesin depletion by inducible proteolytic cleavage of RAD21-TEV; adj. $P<0.05$ based on DEseq2 analysis of 3 RNA-seq replicates per experiment. Two independent experiments are shown. 


\section{Activity-dependent genes are not enriched for CTCF binding}

The transcription of neuronal genes is controlled by neuronal enhancers ${ }^{3,21,22,25-27,29}$. Genes located near constitutive $(n=15695)$ and $\mathrm{KCl}$-inducible $(n=9350)$ neuronal enhancers ${ }^{22}$ were preferentially deregulated in Rad2 $1^{\text {loxlox }} \mathrm{Nex}^{\mathrm{Cre}}$ neurons ${ }^{4}$ (Supplementary Fig. 4a). Activitydependent genes were significantly enriched near neuronal enhancers (Supplementary Fig. 4b). Failure to express activity-dependent genes in cohesin- or CTCF-deficient neurons has been thought to result from a role for cohesin and CTCF in anchoring enhancers to the promoters of activity-dependent neuronal genes ${ }^{3,25,26,29}$. However, analysis of CTCF ChIPseq (Ref. ${ }^{40}$ ) showed that only a minority $(11.8 \%)$ of activity-dependent gene promoters (Supplementary Fig. 4c) were directly bound by CTCF. Similarly, only $\sim 10 \%$ of neuronal enhancers $^{49}$ had CTCF ChIP-seq peaks within $1 \mathrm{~kb}$ (Supplementary Fig. 4c, peaks called at $P<1 \mathrm{E}-04)$. While activity-dependent genes with CTCF promoter binding showed a trend towards more frequent deregulation compared to activity-dependent genes without CTCF promoter binding, this difference was not significant $(P=0.11$, odds ratio $=1.86)$, and we found that more than half $(55.0 \%)$ of all activity-dependent genes that lacked CTCF promoter binding were nevertheless deregulated in $\mathrm{Rad}_{2} 1^{\text {lox/lox }} \mathrm{Nex}{ }^{\mathrm{Cre}}$ neurons (Supplementary Fig. 4d).

While CTCF-based, cohesin-mediated promoter-enhancer loops are demonstrably important for the regulation of a subset of neuronal genes ${ }^{42}$, our analysis indicates that the disruption of direct CTCF-based cohesin-mediated enhancer-promoter loops is not a prerequisite for gene deregulation in cohesin-deficient neurons. This questions the generality of models where the regulation of activity-dependent genes is strictly cohesin- and CTCF-

dependent ${ }^{3,25,26,29}$. An alternative view of gene regulation is that enhancer-promoter interactions are facilitated by CTCF and cohesin not by direct CTCF-based looping, but by increased contact probabilities within CTCF- and cohesin-dependent TADs and contact domains $^{6,711-14}$ (Supplementary Fig. 4e). In this latter scenario, activity-dependent genes, although downregulated at baseline, would still be responsive to signals that induce neuronal activation. To distinguish between these models, we asked to what extent activitydependent genes remained inducible by neuronal activation in the absence of cohesin, and whether such induction would be accompanied by activation-induced enhancer-promoter contacts. 


\section{Activity-dependent genes remain inducible in cohesin-deficient neurons}

To address the impact of cohesin on the dynamic regulation of activity-dependent genes we asked to what extent their expression would remain responsive to neuronal activation signals in Rad21 ${ }^{\text {loxlox }} \mathrm{Nex}{ }^{\mathrm{Cre}}$ neurons. We treated neuronal explant cultures first with tetrodotoxin + D-AP5 (TTX) to block neuronal signaling and then with $\mathrm{KCl}$, a pharmacological inducer of activity-dependent genes, and performed RNA-seq (Fig. 5a; Ref.

${ }^{21}$ ). Consistent with reduced baseline expression of activity-dependent genes, TTX affected more activity-dependent genes in control neurons than in Rad2 $1^{\text {loxlox }} \mathrm{Nex}{ }^{\mathrm{Cre}}(49.5 \%$ versus $28.5 \% ; P=5.89$ e- 11 by two-sample Kolmogorov-Smirnov test; Fig. 5b). TTX reduced the fraction of activity-dependent genes that were downregulated in Rad210x/lox $\mathrm{Nex}$ Cre from 50\% under baseline conditions to $27 \%$ (Fig. 5a, middle). Unexpectedly, the vast majority of genes that were $\mathrm{KCl}$-responsive in control neurons genes remained significantly inducible in Rad2 $1^{\text {loxlox }} \mathrm{Nex}$ Cre neurons $(93.8 \%$ at $1 \mathrm{~h}$ and $97.9 \%$ at $6 \mathrm{~h} \mathrm{KCl}$ treatment, adj. $P<0.05$. Fig. 5c), including early (Npas4, Gadd45b) and late activity-dependent genes (Bdnf, Homer1, Dusp14 Supplementary Fig. 5). For most of these genes, inducibility remained not only statistically significant (adj. $P<0.05$ ), but also robust (adj. $P<0.05$ and log2 fold-change $>$ $1 ; 88.9 \%$ at $1 \mathrm{~h} \mathrm{KCl}$ and $81.4 \%$ at $6 \mathrm{~h} \mathrm{KCl}$ ). Of 154 activity-dependent genes found downregulated at baseline, 76 were 'rescued' to control expression levels. Not all activitydependent genes were induced to normal levels by $\mathrm{KCl}$ treatment of $\mathrm{Rad}_{2} 1^{\text {lox/lox }} \mathrm{Nex}{ }^{\mathrm{Cre}}$ neurons. Some (29\%) failed to reach control levels, while others $(16 \%)$ were expressed at increased levels (Fig. 5a, bottom).

To ask whether activity-dependent genes remained inducible in cohesin-deficient neurons by the physiological stimulus BDNF, we defined genes that responded to BDNF in control cells early or late $(\log 2 \mathrm{FC}>1$, adj. $P<0.05,16$ genes at $30 \mathrm{~min}$ and 261 genes at $120 \mathrm{~min}$ in RAD21-TEV neurons without RAD21-TEV cleavage). Cohesin-deficient neurons continued to show strong induction ( $\log 2 \mathrm{FC}>1$, adj. $P<0.05$ ) of all early BDNF-inducible genes and of most late BDNF-inducible genes (213 of 261, 82\%) 24 hours after RAD21-TEV cleavage (Fig. 5d). 

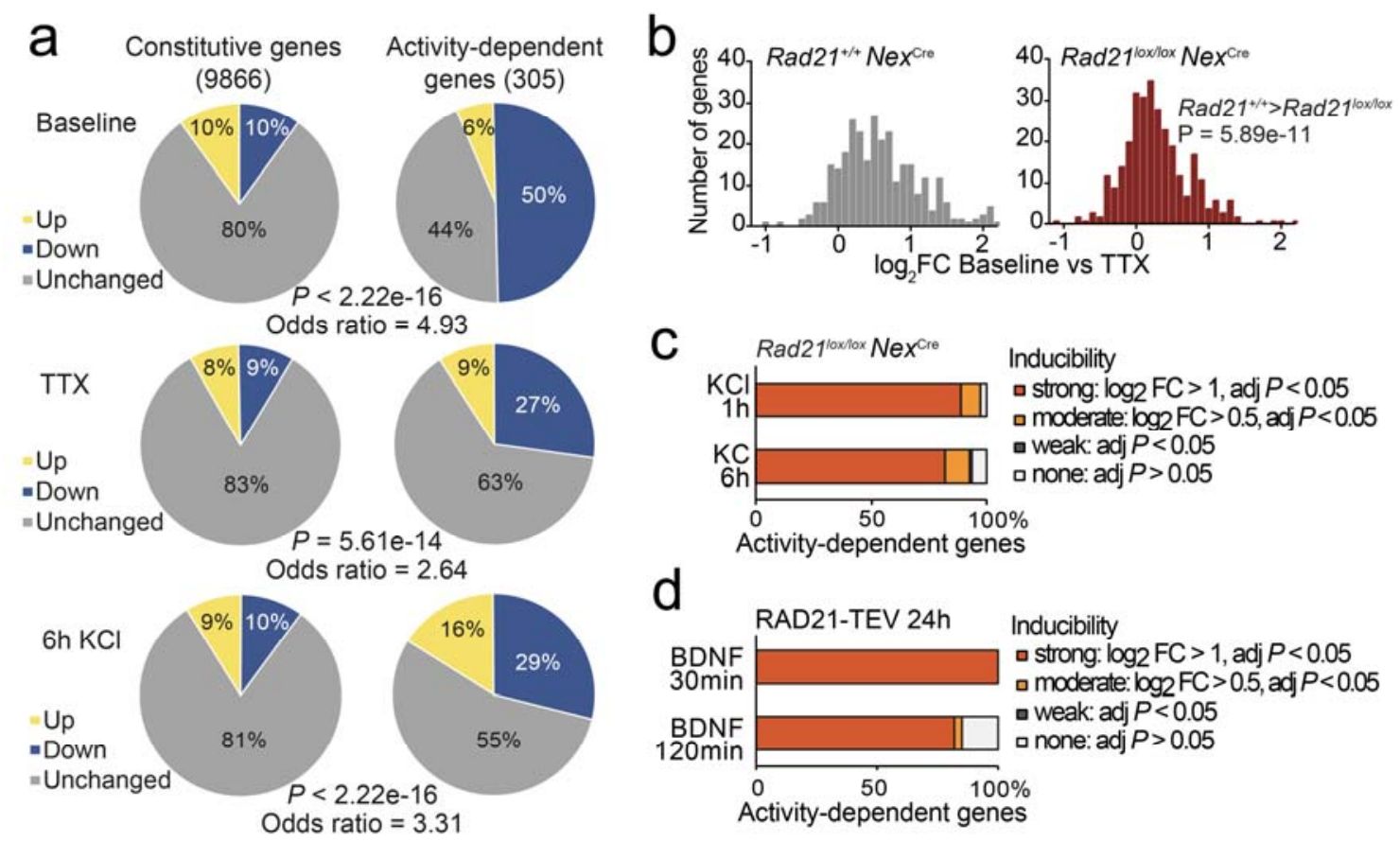

Figure 5. Activity-dependent genes remain inducible in cohesin-deficient neurons

a) Top: The percentage of constitutive and activity-dependent genes deregulated in Rad21 $1^{\text {loxllox }} \mathrm{Nex}$ Cre neurons in explant culture at baseline as determined by RNA-seq. Analysis of previously defined activity-dependent genes ${ }^{21}$. Middle: Fraction of constitutive and activity-dependent genes deregulated in $\mathrm{Rad} 21^{\text {lox/lox }} \mathrm{Nex}{ }^{\mathrm{Cre}}$ neurons in the presence of TTX and D-AP5 (TTX). Bottom: Fraction of constitutive and activity-dependent genes deregulated in $\mathrm{Rad} 21^{\text {lox/lox }} \mathrm{Nex}{ }^{\mathrm{Cre}}$ neurons after 6h stimulation with $\mathrm{KCl}$.

b) Expression of activity-dependent genes in explant cultures of $R$ ad $21^{+/+}$and $R a d 21^{\text {lox/lox }}$ $\mathrm{Ne}{ }^{\mathrm{Cre}}$ neurons under baseline conditions that allow for cell-cell communication versus TTX/D-AP5 (TTX). Comparison by two-sample Kolmogorov-Smirnov test showed that $\mathrm{Rad}_{21^{+/+}} \mathrm{Nex}{ }^{\mathrm{Cre}}$ neurons showed stronger expression of activity-dependent genes than $\operatorname{Rad} 21^{\text {loxlox }} \mathrm{Nex}$ Cre neurons $(P=5.89 \mathrm{e}-11)$.

c) Fraction of activity-dependent genes significantly induced by $\mathrm{KCl}$ in $\mathrm{Rad} 21^{\text {lox/lox }} \mathrm{Nex}$ Cre neurons at 1 and $6 \mathrm{~h}$. In wild-type neurons, 117 and 810 genes were induced $\geq 2$-fold at 1 and $6 \mathrm{~h}$ of $\mathrm{KCl}$ treatment, respectively.

d) Fraction of activity-dependent genes that were significantly induced by BDNF at 30 and 120min in RAD21-TEV neurons 24h after RAD21 cleavage. In control RAD21-TEV neurons, 16 and 261 activity-dependent genes were induced $\geq 2$-fold 30 and 120min after BDNF treatment, respectively. Most of these remained inducible 24h after RAD21-TEV cleavage. Dark orange: Strongly induced: $\log 2 \mathrm{FC}>1$, adj. $P<0.05$; light orange: moderately induced (log2 FC $>0.5$, adj. $P<0.05$ ); grey: weakly induced (adj. $P<0.05$ ); white: not induced (adj. $P$ $>0.05)$. 


\section{Cohesin is not essential for chromatin contacts between inducible enhancers and promoters at the activity-dependent Fos and Arc loci}

To examine the mechanism of inducible activity-dependent gene expression in Rad210x/lox $\mathrm{Nex}{ }^{\mathrm{Cre}}$ neurons we focused on the immediate early response gene Fos. As other activitydependent genes, Fos expression in Rad21 ${ }^{\text {lox/lox }} \mathrm{Nex}$ Cre neurons was reduced at baseline and in the presence of TTX, yet Fos remained inducible when Rad21 $1^{\text {lox/lox }} \mathrm{Nex}$ Cre neurons were stimulated with $\mathrm{KCl}$ (Fig. 6a) or with BDNF (Supplementary Fig. 6). Neuronal Fos enhancers have been extensively characterised ${ }^{27,50}$. Enhancers 1, 2 and 5 are marked by activation-dependent acetylation of H3K27 (H3K27ac), and are actively transcribed in cortical neurons in response to $\mathrm{KCl}\left(\right.$ Ref. ${ }^{50}$ ). Activation-dependent eRNA transcription of Fos enhancers remained intact in $\mathrm{Rad} 21^{\text {lox/lox }} \mathrm{Nex}^{\mathrm{Cre}}$ neurons (Fig. 6b). Activation-induced H3K27ac of Fos enhancers was also preserved in Rad21 1ox/lox Nex ${ }^{\text {Cre }}$ neurons (Fig. 6c). In wild-type neurons, enhancers 1 and 2 show inducible chromatin contacts with the Fos promoter that form rapidly in response to neuronal activation ${ }^{27}$ (Fig. 6d). Unexpectedly, $\operatorname{Rad} 21^{\text {lox/lox }} \mathrm{Nex}{ }^{\mathrm{Cre}}$ neurons retained the ability to robustly and dynamically induce contacts between the Fos promoter and Fos enhancers 1 and 2 (Fig. 6d). Quantification showed that inducible enhancer-promoter contacts at the Fos locus were of comparable strength in control and Rad21 $1^{\text {loxlox }} \mathrm{Nex}$ Cre neurons (Fig. 6e, top and center), while a structural CTCFbased loop surrounding the Fos locus was substantially weakened (Fig. 6e, bottom).

The expression of the immediate early response gene Arc was reduced in $\mathrm{Rad} 21^{\text {lox/lox }} \mathrm{Nex} \mathrm{Cre}^{\mathrm{Cr}}$ neurons at baseline, but, like Fos, Arc remained inducible by stimulation with $\mathrm{KCl}$ (Supplementary Fig. 7a, top) and BDNF (Supplementary Fig. 7a, bottom). Stimulation of wild-type neurons triggers the formation of chromatin contacts between the Arc promoter and an Arc-associated activity-induced enhancer ${ }^{27}$ (Supplementary Fig. 7b). As observed for Fos, Arc promoter-enhancer contacts were retained in $\mathrm{Rad} 21^{\mathrm{lox} / \mathrm{lox}} \mathrm{Nex}$ Cre neurons (Supplementary Fig. 7b, c), while CTCF-based loops surrounding the Arc locus were weakened (Supplementary Fig. 8b, c). In contrast to control neurons, Arc promoter-enhancer contacts became at least partially independent of activation signals $\mathrm{Rad} 21^{\text {loxlox }} \mathrm{Nex}$ Cre neurons (Supplementary Fig. 7b, c).

These data indicate that cohesin is required for the correct baseline expression of activitydependent genes, but largely dispensable for inducible transcription and for specific activation-induced enhancer-promoter contacts (Fig. 6f, see discussion for details). 


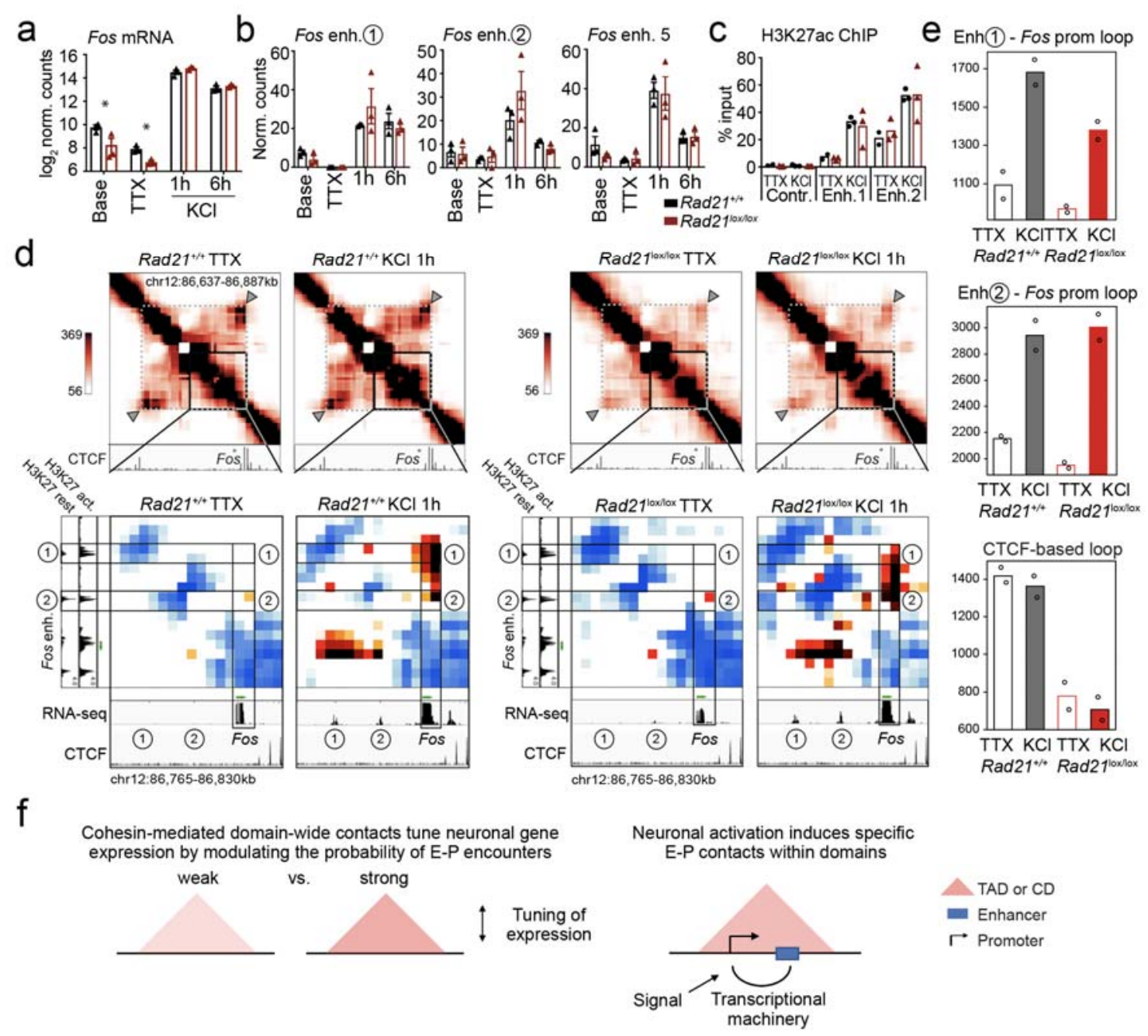

Figure 6. Specific enhancer-promoter contacts can be robustly induced in cohesindeficient neurons.

a) Expression of the activity-dependent Fos gene at baseline, after TTX/D-AP5 (TTX), and $\mathrm{KCl}$-stimulation (left, mean log2-transformed counts from 3 biological replicates, ${ }^{*}$ adj. $\left.P<0.05\right)$.

b) Enhancer transcripts in control and Rad2 $1^{\text {loxlox }} \mathrm{Nex}$ Cre neurons were quantified based on normalized RNA-seq reads within $1 \mathrm{~kb}$ of the eRNA transcription start site. An intergenic region on chr11 was used as a negative control (71.177.622-71.177.792).

c) H3K27ac ChIP normalized to H3 in control and Rad2 $1^{\text {lox/lox }} \mathrm{Nex}$ Cre neurons at a control site, Fos enhancer 1 and Fos enhancer 2 after TTX/D-AP5 (TTX) or $1 \mathrm{~h} \mathrm{KCl}(\mathrm{KCl})$.

d) Interaction score heatmaps of the $65 \mathrm{~kb}$ region immediately surrounding Fos obtained by 5C. Black frames highlight interactions between the Fos gene and upstream enhancers 1 and 2. Previously published ${ }^{40}$ CTCF-ChIP-seq is shown for orientation and H3K27ac ChIPseq in inactive (TTX-treated) and activated neurons is shown to annotate enhancer 
regions $^{27}$. RNA-seq in TTX-treated and $1 \mathrm{~h} \mathrm{KCl-activated} \mathrm{control} \mathrm{and} \mathrm{Rad}_{2} 1^{\text {lox/lox }} \mathrm{Nex}$ Cre neurons shows $\mathrm{KCl}$-inducible transcription of Fos enhancers in wild-type and cohesindeficient neurons. Two independent biological replicates are shown in Supplementary Fig. $8 a$.

e) Quantification of 5C contacts between the Fos promoter and Fos enhancer 1 (top), the Fos promoter and Fos enhancer 2 (middle), and CTCF-marked boundaries of the sub-TAD containing Fos (bottom). Two replicates per genotype and condition.

f) Model for how cohesin-mediated domain-wide contacts alter the probability of enhancerpromoter contacts, and in this way fine-tune the transcription of activity-dependent genes at baseline and in response to activation. In the absence of cohesin, many activity-dependent genes are expressed at inappropriate levels, but most remain responsive to inducing activation signals. At the Fos and Arc loci, cohesin is not required for chromatin contacts between inducible enhancers and their target promoters. See text for details.

\section{Discussion}

Experimental depletion of cohesin in immature post-mitotic neurons defines a role for cohesin in neuronal gene expression and neuronal maturation. We find extensive downregulation of genes related to synaptic transmission, connectivity, neuronal development and signaling in $\mathrm{Rad}_{2} 1^{\text {lox/lox }} \mathrm{Nex}{ }^{\mathrm{Cre}}$ neurons. These gene classes are central to neuronal identity, and their wide-spread downregulation is likely to contribute to the observed maturation defects of Rad2 $1^{\text {lox lox }} \mathrm{Nex}$ Cre neurons. Acute proteolysis of RAD21-TEV and longer-term genetic cohesin depletion in Rad2 $1^{\text {lox/lox }} \mathrm{Nex}$ Cre neurons corroborated a prominent role for cohesin in the expression of genes that facilitate neuronal maturation, homeostasis, and activation. In agreement with earlier studies, we find that the expression of activity-dependent genes is highly dependent on cohesin ${ }^{3,25,26}$. Unexpectedly, the inducibility of activity-dependent genes was largely preserved, and specific enhancer-promoter contacts remained inducible in cohesin-deficient neurons.

Earlier work had shown that 3D genome organization can remain largely intact in cells that are partially depleted of $\operatorname{cohesin}^{38,51,52}$ or CTCF (Refs. ${ }^{9,51}$ ). In the Nex ${ }^{\mathrm{Cre}}$ Rad21 system, cohesin is depleted to undetectable levels in $\mathrm{Nex}^{\mathrm{Cre}}$-expressing cells, which comprise $\sim 80 \%$ of neuronal explant cultures. Importantly, this depletion substantially reduces the strength of CTCF-based chromatin loops. The observation that the inducibility of activity-dependent genes and of specific enhancer-promoter contacts were retained in this setting underscores that the underlying mechanisms operate independently of cohesin. 
Precedent for cohesin-independent contacts between promoters and enhancers comes from studies where auxin-induced degradation of RAD21 in HeLa cells removed most pre-existing enhancer-promoter interactions, while others persisted in the absence of $\operatorname{cohesin}^{53}$. Ectopic cross-boundary contacts formed when existing boundaries were removed ${ }^{53}$. In contrast to such persistent or ectopic contacts, the enhancer-promoter contacts described here are physiological and specific, and enable the regulated expression of activity-dependent genes. At the Fos locus, enhancers show signal-responsive induction of H3K27ac as well as inducible transcription, and engage in signal-dependent promoter contacts to enable the regulated activity-dependent gene expression in $\mathrm{Rad}_{2} 1^{\text {lox/lox }} \mathrm{Nex} \mathrm{Cre}^{\mathrm{Cr}}$ neurons.

The activation of inducible Fos enhancers involves H3K27ac (Ref. ${ }^{27}$ ), recruitment of RNA polymerases $^{28}$ and Mediator complex ${ }^{25}$, as well as active transcription ${ }^{50}$. Our data show that cohesin is not required for the recruitment of histone acetyl transferase activity and of the transcriptional machinery to inducible Fos enhancers. Importantly, RNAP2, Mediator, the transactivation domains of sequence-specific transcription factors and the C-terminal domain of the chromatin reader BRD4 contain intrinsically disordered domains that support the formation of molecular condensates enriched for transcriptional mediators ${ }^{30-34}$. The formation of such condensates ${ }^{30,32}$ is guided by specific sequences in the underlying chromatin template ${ }^{34}$ and can actively contribute to nuclear topology $y^{54,55}$. These and related findings ${ }^{35}$ suggest mechanisms that converge with cohesin to confer robustness to the formation of enhancer-promoter contacts.

While our results highlight the robustness to E-P contacts to the loss of cohesin, other recent studies have shown that E-P contacts can be resilient to the loss or inhibition of components of the transcriptional machinery such as Mediator ${ }^{37}$ and BRD4 (Ref. ${ }^{36}$ ). Although cohesin belongs to an evolutionarily ancient family of SMC protein complexes ${ }^{5}$, specific interactions of cohesin with CTCF are a relatively recent innovation of genome organisation in vertebrates ${ }^{56}$. Enhancer-promoter contacts clearly pre-date this innovation, as illustrated for example in $D$. melanogaster, where transcription-based mechanisms contribute ${ }^{57}$. High resolution techniques such as deep in situ Hi-C (Ref. ${ }^{40}$ ) and micro-C (Ref. ${ }^{58,59}$ ) have revealed an abundance of chromatin contacts, only some of which are based on direct CTCF binding. Hence, as gene regulatory mechanisms have become more complex and the number and distance of regulatory elements have increased, convergent mechanisms have been co-opted, which cooperate in the establishment and maintenance of enhancerpromoter contacts in vertebrates ${ }^{30-37,60}$. 
Our data suggest a revised perspective for the regulation of inducible genes (Fig. 6f) where cohesin and CTCF are important not primarily for new enhancer-promoter loops in response to activating stimuli, but for forming CTCF-based self-interacting domains ${ }^{6,7,11-14}$. For the majority of neuronal genes, this CTCF-based framework facilitates appropriate expression by modulating probabilistic interactions between genes and enhancers rather than forming direct, CTCF-based enhancer-promoter loops. In the absence of cohesin, the framework of CTCF-based contacts is weakened, and many neuronal genes are expressed at inappropriate levels. However, the majority of activity-dependent genes remain responsive to inducing signals and, at the Fos and Arc loci at least, chromatin contacts between inducible enhancers and their target promoters are robust to cohesin depletion.

Acknowledgements. We thank G. Little, M. Clements, and S. Parrinello (University College London) for advice and practical instruction, S. Di Giovanni and J. Merkenschlager (Rockefelller University) for comments on the manuscript, L. Game for sequencing, and J. Elliott and B. Patel for cell sorting. This work was funded by the Medical Research Council UK, The Wellcome Trust (Investigator Award 099276/Z/12/Z to MM), EMBO and HFSP (HFSP LT00427/2013, EMBO ALTF 1047-2012 TO LC).

Author contributions. LC, FDW, JAB, MSO, WG and KT did experiments, LC, FDW, JAB, MSO, Y-FW, TC, GD, KT, and MM analysed data, LC, FDW, JAB, MAU, AGF, JEP-C and MM conceptualised the study, CW provided tools for image acquisition and analysis; LC, FDW, JAB, AGF, JEP-C and MM wrote the manuscript.

Competing interests. The authors declare that they have no competing interest.

Data availability. RNAseq and 5C data generated in this study have been deposited at Gene Expression Omnibus under accession number GSE122277.

\section{References}

1 Deardorff, M. A., Noon, S. E. \& Krantz, I. D. Cornelia de Lange Syndrome. in GeneReviews ${ }^{\circledR}$ (eds. Adam, M. P. et al.) (University of Washington, Seattle, 2018).

2 Gregor, A. et al. De novo mutations in the genome organizer CTCF cause intellectual disability. Am J Hum Genet 93, 124-31 (2013).

3 Rajarajan, P., Gil, S. E., Brennand, K. J. \& Akbarian, S. Spatial genome organization and cognition. Nat. Rev. Neurosci. 17, 681-691 (2016). 
4 Weiss FD, Calderon L, Wang Y-F, Georgieva R, Guo Y, Cvetesic N, Kaur M, Dharmalingam G, Krantz ID, Lenhard B, Fisher AG, Merkenschlager M. Partial rescue of neuronal genes deregulated in Cornelia de Lange Syndrome by cohesin. bioRxiv 2020.06.06.136432 (2020)

5 Nasmyth, K. \& Haering, C. H. Cohesin: its roles and mechanisms. Annu Rev Genet 43, 525-58 (2009).

6 Fudenberg, G. et al. Formation of Chromosomal Domains by Loop Extrusion. Cell Rep. 15, 2038-2049 (2016).

7 Rao, S. S. P. et al. A 3D map of the human genome at kilobase resolution reveals principles of chromatin looping. Cell 159, 1665-1680 (2014).

8 Rao, S. S. P. et al. Cohesin Loss Eliminates All Loop Domains. Cell 171, 305-320.e24 (2017).

9 Nora, E. P. et al. Targeted Degradation of CTCF Decouples Local Insulation of Chromosome Domains from Genomic Compartmentalization. Cell 169, 930-944.e22 (2017).

10 Schwarzer, W. et al. Two independent modes of chromatin organization revealed by cohesin removal. Nature 551, 51-56 (2017).

11 Dekker, J. \& Mirny, L. The 3D Genome as Moderator of Chromosomal Communication. Cell 164, 1110-1121 (2016).

12 Merkenschlager, M. \& Nora, E. P. CTCF and Cohesin in Genome Folding and Transcriptional Gene Regulation. Annu. Rev. Genomics Hum. Genet. 17, 17-43 (2016).

13 McCord, R., Kaplan, N. \& Giorgetti, L. Chromosome Conformation Capture and Beyond: Toward an Integrative View of Chromosome Structure and Function. Molecular Cell 77, 688708 (2020)

14 Kim S, Shendure J. Mol Cell. Mechanisms of Interplay between Transcription Factors and the 3D Genome. 2019 Oct 17;76(2):306-319. doi: 10.1016/j.molcel.2019.08.010.

15 Lupiáñez, D. G. et al. Disruptions of Topological Chromatin Domains Cause Pathogenic Rewiring of Gene-Enhancer Interactions. Cell 161, 1012-1025 (2015).

16 Spielmann, M., Lupiáñez, D. G. \& Mundlos, S. Structural variation in the 3D genome. Nat. Rev. Genet. 19, 453-467 (2018).

17 Won, $\mathrm{H}$. et al. Chromosome conformation elucidates regulatory relationships in developing human brain. Nature 538, 523-527 (2016).

18 Goebbels, S. et al. Genetic targeting of principal neurons in neocortex and hippocampus of NEX-Cre mice. Genesis 44, 611-21 (2006).

19 Hirayama, T., Tarusawa, E., Yoshimura, Y., Galjart, N. \& Yagi, T. CTCF is required for neural development and stochastic expression of clustered Pcdh genes in neurons. Cell Rep. 2, 345-57 (2012).

20 Gallo, F.T., Katche, C., Morici, J.F., Medina, J.H., and Weisstaub, N.V. Immediate Early Genes, Memory and Psychiatric Disorders: Focus on c-Fos, Egr1 and Arc. Front Behav Neurosci 12, 79. (2018)

$21 \mathrm{Kim}, \mathrm{T}$. K. et al. Widespread transcription at neuronal activity-regulated enhancers. Nature 465, 182-7 (2010).

22 Malik, A. N. et al. Genome-wide identification and characterization of functional neuronal activity-dependent enhancers. Nat Neurosci. 17: 1330-9. doi: 10.1038/nn.3808 (2014).

23 Greer, P. L. \& Greenberg, M. E. From synapse to nucleus: calcium-dependent gene transcription in the control of synapse development and function. Neuron 59, 846-60 (2008). 
24 Yap, E.L., and Greenberg, M.E. Activity-Regulated Transcription: Bridging the Gap between Neural Activity and Behavior. Neuron 100, 330-348.(2018)

25 Schaukowitch, K. et al. Enhancer RNA facilitates NELF release from immediate early genes. Mol. Cell 56, 29-42 (2014).

26 Yamada T, Yang Y, Valnegri P, Juric I, Abnousi A, Markwalter KH, Guthrie AN, Godec A, Oldenborg A, Hu M, Holy TE, Bonni A. Sensory experience remodels genome architecture in neural circuit to drive motor learning. Nature. 2019 May;569(7758):708-713.

27 Beagan JA, Pastuzyn ED, Fernandez LR, Guo MH, Feng K, Titus KR, Chandrashekar H, Shepherd JD, Phillips-Cremins JE. Three-dimensional genome restructuring across timescales of activity-induced neuronal gene expression. Nat Neurosci. 2020 Jun;23(6):707717. doi: 10.1038/s41593-020-0634-6.

28 Kim B, Luo Y, Zhan X, Zhang Z, Shi X, Yi J, Xuan Z, Wu J. Neuronal Activity-Induced BRG1 Phosphorylation Regulates Enhancer Activation. bioRxiv 2020.09.01.278101 (2020)

29 Sams, D. S. et al. Neuronal CTCF is Necessary for Basal and Experience-Dependent Gene Regulation, Memory Formation, and Genomic Structure of BDNF and Arc. Cell Rep. 17, 2418-2430 (2016).

30 Sabari, B. R. et al. Coactivator condensation at super-enhancers links phase separation and gene control. Science 361, eaar3958 (2018).

31 Boija, A. et al. Transcription factors activate genes through the phase-separation capacity of their activation domains. Cell 175, 1842-1855 e16 (2018).

32 Cho WK, Spille JH, Hecht M, Lee C, Li C, Grube V, Cisse II. Mediator and RNA polymerase II clusters associate in transcription-dependent condensates. Science. 2018 361: $412-415$ (2018)

$33 \mathrm{Li}$ J, Dong A, Saydaminova K, Chang H, Wang G, Ochiai H, Yamamoto T, Pertsinidis A. Single-Molecule Nanoscopy Elucidates RNA Polymerase II Transcription at Single Genes in Live Cells. Cell. Jul 11;178(2):491-506.e28. 2019

34 Li J, Hsu A, Hua Y, Wang G, Cheng L, Ochiai H, Yamamoto T, Pertsinidis A. Single-gene imaging links genome topology, promoter-enhancer communication and transcription control. Nature Struct. Mol. Biol. (2020)

35 Wang $\mathrm{S}, \mathrm{Hu} \mathrm{H}, \mathrm{Li}$. Hundreds of motif pairs may facilitate enhancer-promoter interactions. BioRxiv 10.1101/2020.12.29.424656 (2020)

36 Crump NT, Ballabio E, Godfrey L, Thorne R, Repapi E, Kerry J, Tapia M, Hua P, Filippakopoulos P, Davies J. O. J., Milne T.A. BET inhibition disrupts transcription but retains enhancer-promoter contact BET inhibition disrupts transcription but retains enhancerpromoter contact. Nat Commun. 12, 223. doi: 10.1038/s41467-020-20400-z.

37 El Khattabi L, Zhao H, Kalchschmidt J, Young N, Jung S, Van Blerkom P, Kieffer-Kwon P, Kieffer-Kwon KR, Park S, Wang X, Krebs J, Tripathi S, Sakabe N, Sobreira DR, Huang SC, Rao SSP, Pruett N, Chauss D, Sadler E, Lopez A, Nóbrega MA, Aiden EL, Asturias FJ, Casellas R. A Pliable Mediator Acts as a Functional Rather Than an Architectural Bridge between Promoters and Enhancers. Cell 178:1145-1158.e20. (2019)

38 Seitan, V. C. et al. A role for cohesin in T-cell-receptor rearrangement and thymocyte differentiation. Nature 476, 467-71 (2011).

39 Sanz, E. et al. Cell-type-specific isolation of ribosome-associated mRNA from complex tissues. Proc Natl Acad Sci U A 106, 13939-44 (2009).

40 Bonev B, Mendelson Cohen N, Szabo Q, Fritsch L, Papadopoulos GL, Lubling Y, Xu X, Lv X, Hugnot JP, Tanay A, Cavalli G. Multiscale 3D Genome Rewiring during Mouse Neural Development. Cell 171: 557-572 (2017) 
41 Banerjee-Basu, S. \& Packer, A. SFARI Gene: an evolving database for the autism research community. Dis. Model. Mech. 3, 133-135 (2010).

42 Guo, Y. et al. CRISPR Inversion of CTCF Sites Alters Genome Topology and Enhancer/Promoter Function. Cell 162, 900-910 (2015).

43 Kawauchi, S. et al. Multiple organ system defects and transcriptional dysregulation in the $\mathrm{Nipbl(+/-)} \mathrm{mouse,} \mathrm{a} \mathrm{model} \mathrm{of} \mathrm{Cornelia} \mathrm{de} \mathrm{Lange} \mathrm{Syndrome.} \mathrm{PLoS} \mathrm{Genet} \mathrm{5,} \mathrm{e1000650}$ (2009).

44 Remeseiro, S., Cuadrado, A., Gomez-Lopez, G., Pisano, D. G. \& Losada, A. A unique role of cohesin-SA1 in gene regulation and development. EMBO J. 31, 2090-102 (2012).

45 van den Berg, D. L. C. et al. Nipbl Interacts with Zfp609 and the Integrator Complex to Regulate Cortical Neuron Migration. Neuron 93, 348-361 (2017).

46 Kaech, S. \& Banker, G. Culturing hippocampal neurons. Nat. Protoc. 1, 2406-15 (2006).

47 Sholl, D. A. Dendritic organization in the neurons of the visual and motor cortices of the cat. J. Anat. 87, 387-406.1 (1953).

48 Greig, L. C., Woodworth, M. B., Galazo, M. J., Padmanabhan, H. \& Macklis, J. D. Molecular logic of neocortical projection neuron specification, development and diversity. Nat. Rev. Neurosci. 14, 755-769 (2013).

49 Osterwalder, M. et al. Enhancer redundancy provides phenotypic robustness in mammalian development. Nature 554, 239-243 (2018).

50 Joo JY, Schaukowitch K, Farbiak L, Kilaru G, Kim TK. Stimulus-specific combinatorial functionality of neuronal c-fos enhancers. Nat Neurosci. 2016 Jan;19(1):75-83.

51 Zuin J, Dixon JR, van der Reijden MI, Ye Z, Kolovos P, Brouwer RW, van de Corput MP, van de Werken HJ, Knoch TA, van IJcken WF, Grosveld FG, Ren B, Wendt KS. Cohesin and CTCF differentially affect chromatin architecture and gene expression in human cells. Proc Natl Acad Sci U S A. 111: 996-1001 (2014)

52 Sofueva S, Yaffe E, Chan WC, Georgopoulou D, Vietri Rudan M, Mira-Bontenbal H, Pollard SM, Schroth GP, Tanay A, Hadjur S. EMBO J. 2013; 32: 3119-29.

53 Thiecke MJ, Wutz G, Muhar M, Tang W, Bevan S, Malysheva V, Stocsits R, Neumann T, Zuber J, Fraser P, Schoenfelder S, Peters JM, Spivakov M. Cohesin-Dependent and Independent Mechanisms Mediate Chromosomal Contacts between Promoters and Enhancers. Cell Rep. 2020 Jul 21;32(3):107929.

54 Shin Y, Chang YC, Lee DSW, Berry J, Sanders DW, Ronceray P, Wingreen NS, Haataja M, Brangwynne CP. Liquid Nuclear Condensates Mechanically Sense and Restructure the Genome. Cell. 175: 1481-1491.e13 (2018)

55 Brangwynne CP. Liquid Nuclear Condensates Mechanically Sense and Restructure the Genome. Cell. 2019 Mar 7;176(6):1518. doi: 10.1016/j.cell.2019.02.025.

56 Li Y, Haarhuis JHI, Sedeño Cacciatore Á, Oldenkamp R, van Ruiten MS, Willems L, Teunissen H, Muir KW, de Wit E, Rowland BD, Panne D. The structural basis for cohesinCTCF-anchored loops. Nature 578: $472-476$ (2020)

57 Rowley MJ, Corces VG. Organizational principles of 3D genome architecture. Nat Rev Genet. 19: 789-800 (2018)

58 Hsieh TS, Cattoglio C, Slobodyanyuk E, Hansen AS, Rando OJ, Tjian R, Darzacq X. Resolving the 3D Landscape of Transcription-Linked Mammalian Chromatin Folding. Mol Cell. 78: 539-553.e8 (2020) 
59 Krietenstein N, Abraham S, Venev SV, Abdennur N, Gibcus J, Hsieh TS, Parsi KM, Yang L, Maehr R, Mirny LA, Dekker J, Rando OJ. Ultrastructural Details of Mammalian Chromosome Architecture. Mol Cell. 78: 554-565.e7 (2020)

60 Hadjur S, Williams LM, Ryan NK, Cobb BS, Sexton T, Fraser P, Fisher AG, Merkenschlager $\mathrm{M}$. Cohesins form chromosomal cis-interactions at the developmentally regulated IFNG locus. Nature 460: 410-3 (2009)

\section{Methods}

Mice. Mouse work was done under a UK Home Office project licence and according to the Animals (Scientific Procedures) Act. Mice carrying the floxed Rad21 allele (Rad21 ${ }^{10 x}$, Ref. ${ }^{38}$ ), in combination with the Cre recombinase in the Nex locus ( $\mathrm{Nex}{ }^{\mathrm{Cre}}$, Ref. ${ }^{18}$ ) and where indicated Rpl22(HA) lox/lox RiboTag (Ref. ${ }^{39}$ ) were on a mixed C57BL/129 background. For timed pregnancies the day of the vaginal plug was counted as day 0.5. Genotypes were determined by PCR as previously reported ${ }^{38,39}$. Rad $21^{\text {tev/tev }}$ mice have been described ${ }^{4,61,62}$.

Neuronal cultures. For $\mathrm{Nex}^{\mathrm{Cre}}$ experiments, mouse cortices were dissected and dissociated from individual E17.5-E18.5 mouse embryos as described ${ }^{63}$ with minor modifications. Dissociated neurons were maintained in Neurobasal medium with B27 supplement (Invitrogen), $1 \mathrm{mM} \mathrm{L}$-glutamine, and $100 \mathrm{U} / \mathrm{mL}$ penicillin/streptomycin for 10 days in vitro. Cells were plated at a density of $0.8 \times 10^{6}$ cells per well on 6 -well plates pre-coated overnight with $0.1 \mathrm{mg} / \mathrm{ml}$ poly-D-lysine (Millipore) and one third of the media in each well was replaced every 3 days. Cultures were treated with $5 \mu \mathrm{M}$ Cytosine $\beta$-D-arabinofuranoside (Ara-C, Sigma) from day 2-4. For immunofluorescence staining neurons were plated on 12 $\mathrm{mm}$ coverslips (VWR) coated with poly-D-lysine at a density of $0.1 \times 10^{6}$ cells per coverslip. For cell-type-specific isolation of ribosome-associated mRNA, neurons from both cortices from each individual mouse embryo were seeded in a $10 \mathrm{~cm}$ dish.

For RAD21-TEV experiments, mouse cortices were dissected and dissociated on E14.5 15.5 as described ${ }^{4}$. Neurons were maintained in Neurobasal medium with B27 supplement (Invitrogen), $1 \mathrm{mM} \mathrm{L-glutamine,} \mathrm{and} 100 \mathrm{U} / \mathrm{ml}$ penicillin/streptomycin. Cells were plated at a density of $1.25 \times 10^{5} / \mathrm{cm}^{2}$ on $0.1 \mathrm{mg} / \mathrm{ml}$ poly-D-lysine (Millipore) coated plates, and half the media was replaced every 3 days. Cultures were treated with $5 \mu \mathrm{M}$ Ara-C at day 5 . For cleavage of RAD21-TEV, neurons were plated as described above and transduced at day 3 with lentivirus containing ERt2-TEV at a multiplicity of infection of 1. For ERt2-TEV dependent RAD21-TEV degradation, neurons were treated on culture day 10 with 500nM 4hydroxytamoxifen (4-OHT) or vehicle (ethanol) for 24 hours.

For $\mathrm{KCl}$ depolarization experiments, neuronal cultures were pre-treated with $1 \mu \mathrm{M}$

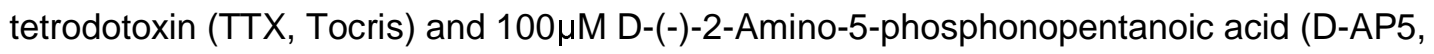
Tocris) overnight to reduce endogenous neuronal activity prior to stimulation. Neurons were membrane depolarized with $55 \mathrm{mM}$ extracellular $\mathrm{KCl}$ by addition of prewarmed depolarization buffer (170 mM KCl, $2 \mathrm{mM} \mathrm{CaCl} 2,1 \mathrm{mM} \mathrm{MgCl}$, $10 \mathrm{mM} \mathrm{HEPES} \mathrm{pH7.5)} \mathrm{to} \mathrm{a}$ proportion of 0.43 volumes per $1 \mathrm{ml}$ volume of neuronal culture medium in the well. For BDNF induction experiments, neuronal cultures were treated with BDNF $(50 \mathrm{ng} / \mathrm{ml})$ for the indicated period of time at 10 days in vitro. 
For Sholl analysis, dissociated cortical neurons were cultured as described ${ }^{46}$. Astroglial monolayers were adhered to culture dishes and cortical neurons to coverslips, which were then suspended above the glia. Primary cultures of glial cells were prepared from newborn rat cortices. Four days before neuronal culture preparation, glial cells were seeded in 12-well plates at a density of $1 \times 10^{4}$ cells per well and one day before, the medium from the glial feeder cultures was removed and changed to neuronal maintenance medium for preconditioning. Mouse cortices were dissected from E17.5/E18.5 mouse embryos and kept up to $24 \mathrm{~h}$ in $2 \mathrm{~mL}$ of Hibernate ${ }^{\mathrm{TM}}$-E Medium (ThermoFisher) containing B27 supplement (Invitrogen) and $1 \mathrm{mM} \mathrm{L-glutamine} \mathrm{in} \mathrm{the} \mathrm{dark} \mathrm{at} 4^{\circ} \mathrm{C}$. Embryos were genotyped and the cortices from the desired genotypes were used to prepare neuronal cultures as described before. Neurons were plated on 24-well plates containing poly-D-lysine precoated $12 \mathrm{~mm}$ coverslips (VWR) at a density of $0.1 \times 10^{6}$ cells per well. Wax dots were applied to the coverslips, which served as 'feet' to suspend the coverslips above the glial feeder layer. Four hours after neuronal seeding, each coverslip containing the attached neurons was transfer upside down into a well of the 12-well dishes with the glial feeder. Cultures were treated with $5 \mu \mathrm{M}$ Ara-C from day 2-4 and subsequently one third of the media was replaced every 3 days. For sparse neuronal GFP labelling, cortical neurons were transfected using $1 \mu \mathrm{g}$ of peGFP-N1 plasmid along with $2 \mu \mathrm{l}$ per well of Lipofectamine 2000 (Invitrogen) after 12 days in culture. Cultures were maintained for 14 days in vitro before fixation.

RNA extraction and RT-qPCR. RNA was extracted with QIAshredder and RNeasy minikit (Qiagen). Residual DNA was eliminated using DNA-free kit (Ambion) and reversetranscribed using the SuperScript first-strand synthesis system (Invitrogen). RT-PCR was performed on a CFX96 Real-Time System (Bio-Rad) with SYBR Green Master Mix (BioRad) as per the manufacturer's protocol and normalized to Ubc and Hprt mRNA levels. Relative level of the target sequence against the reference sequences was calculated using the $\Delta \Delta$ cycle threshold method. RT-PCR primer sequences:

\begin{tabular}{|l|l|l|}
\hline Gene & Forward (5'- 3') $^{\prime}$ & Reverse (5'- 3') $^{\prime}$ \\
\hline Ubc & AGGAGGCTGATGAAGGAGCTTGA & TGGTTTGAATGGATACTCTGCTGGA \\
\hline Hprt & CCTGCTAATTTTACTGGCAACATCAACA & TTGAAATTCCAGACAAGTTTGTTGTTGG \\
\hline Rad21 & AGCACCAGCAACCTGAATGA & GATCGTCAAAGATGCCACCA \\
\hline Arc & TACCGTTAGCCCCTATGCCATC & TGATATTGCTGAGCCTCAACTG \\
\hline Fos & AATGGTGAAGACCGTGTCAGGA & TTGATCTGTCTCCGCTTGGAGTGT \\
\hline Cdkn1a & GCAGACCAGCCTGACAGATT & GAGGGCTAAGGCCGAAGA \\
\hline Mdm2 & TGTGTGAGCTGAGGGAGATG & CACTTACGCCATCGTCAAGA \\
\hline Cdkn2a & AATCTCCGCGAGGAAAGC & GTCTGCAGCGGACTCCAT \\
\hline Cdkn2b & AGACTGCAAGCACGAAGAGG & TTGTCTTACTGGGTAGGGTTCAA \\
\hline
\end{tabular}

Protein analysis. Whole cell extracts were prepared by resuspending cells in PBS with complete proteinase inhibitor (Roche, Cat\#18970600), centrifugation, and resuspension in protein sample buffer (50mM Tris-HCl pH6.8, 1\% SDS, 10\% glycerol) followed by quantification using Qubit. Following quantification 0.001\% Bromophenol blue and 5\% betamercaptoethanol were added. Sodium dodecyl sulphate-polyacrylamide gel electrophoresis (SDS-PAGE) was carried out with the Bio-Rad minigel system. $20 \mu \mathrm{g}$ of protein sample and the benchmark pre-stained protein ladder (Biorad, \#161-0374) were loaded on to a precast 
$10 \%$ polyacrylamide gel (Biorad, \#456-1036). Resolved gels were blotted to a polyninylidene fluoride transfer membrane (Millipore, \#IPVH00010) in transfer buffer (48mM Trizma base, $39 \mathrm{mM}$ glycine, $0.037 \%$ SDS and $20 \%$ methanol) using the trans-blot semi-dry electrophoretic transfer apparatus (BioRad). Membranes were incubated for 1 hour with fluorescent blocker (Millipore, HC-08) followed by primary antibody incubation diluted in blocker at an appropriate dilution for 2 hours or at room temperature or overnight at $4^{\circ} \mathrm{C}$. Primary antibodies were rabbit polyclonal to RAD21 (1:1000; ab154769, Abcam), goat polyclonal to LAMIN B (1:10000; sc-6216; Santa Cruz Biotechnology), mouse monoclonal anti-myc tag (1:500, SC-40, Santa Cruz Biotechnology). Secondary antibodies were goat anti-rabbit IgG $(\mathrm{H}+\mathrm{L})$ Alexa Fluor 680 (1:10000; A-21109, ThermoFisher), goat anti-mouse lgG, Alexa Fluor 680 1:10,000), and donkey anti-goat IgG $(H+L)$ Alexa Fluor 680 (1:10000; A-21084, ThermoFisher). Immobilon-FL PVDF membranes (Millipore) were imaged on an Odyssey instrument (LICOR).

Cell-type-specific isolation of ribosome-associated mRNA. For polysome immunoprecipitation experiments, homogenates from 10 day cortical explant cultures were prepared as described ${ }^{39}$ with minor modifications. Cells were first washed two times on ice with $10 \mathrm{ml}$ of PBS containing $100 \mu \mathrm{g} / \mathrm{mL}$ cycloheximide (Sigma). Cells were lysed in $50 \mathrm{mM}$ Tris pH 7.5, $100 \mathrm{mM} \mathrm{KCl}, 12$ mM MgCl2 (ThermoFisher), 1\% IGEPAL CA-630 (Sigma), 1 mM DTT (Sigma), $200 \mathrm{U} / \mathrm{mL}$ RNasin (ThermoFisher), $1 \mathrm{mg} / \mathrm{mL}$ heparin (Sigma), $100 \mu \mathrm{g} / \mathrm{mL}$ cycloheximide, $1 \mathrm{x}$ Protease inhibitor (Sigma) and homogenization with a motor-driven grinder and pestle for about 2 minutes. Samples were then centrifuged at $10,000 \mathrm{~g}$ for 10 min to create a postmitochondrial supernatant. For immunoprecipitations, $100 \mu \mathrm{L}$ of Dynabeads $^{\mathrm{TM}}$ Protein $\mathrm{G}$ (Invitrogen) were coupled directly to $10 \mu \mathrm{L}$ of rabbit anti-HA antibody (Sigma, H6908). After polysome immunoprecipitation, total RNA was prepared using a RNeasy Plus Mini kit (Qiagen).

RNAseq analysis. Total RNA was obtained in parallel from 10 day explant cultures of dissociated cortical neurons without stimulation (baseline); after overnight treatment with TTX and D-AP5 (TTX); and after overnight treatment with TTX and D-AP5 and depolarization with $\mathrm{KCl}$ for $1 \mathrm{~h}$ (KCl1h) or 6h (KCl6h). RNA was extracted with QIAshredder and RNeasy mini kit (Qiagen). RNA-seq libraries were prepared from $600 \mathrm{ng}$ of total RNA (RNA integrity number $(\mathrm{RIN})>8.0$ ) with TruSeq Stranded Total RNA Human/Mouse/Rat kit (Illumina). For polysome immunoprecipitation experiments, $300 \mathrm{ng}$ of total RNA was used for library preparation (RIN>9.0). RNA from Rad21-TEV neurons was purified with a PicoPure RNA Isolation kit (Applied Biosystems KIT0204), and 200ng of total RNA was used to prepare libraries using the NEBNext ${ }^{\circledR}$ Ultra ${ }^{\text {TM }}$ II Directional RNA Library Prep Kit for Illumina (polyA enrichment), following the manufacturer recommendations. Library quality and quantity were assessed on a Bionalayser and Qubit respectively. Libraries were sequenced on an Illumina Hiseq2500 (v4 chemistry) and at least 40 million paired end $100 \mathrm{bp}$ reads per sample were generated per library and mapped against the mouse (mm9) genome. The quality of RNA-seq reads was checked by Fastqc (https://www.bioinformatics.babraham.ac.uk/projects/fastqc/) and aligned to mouse genome mm9 using Tophat version 2.0.11 (Ref. ${ }^{64}$ ) with parameters "--library-type=fr-firststrand". Gene coordinates from Ensembl version 67 were used as gene model for alignment. Quality metrics for the RNA-Seq alignment were computed using Picard tools verion 1.90 (https://broadinstitute.github.io/picard/). Genome wide coverage for each sample was 
generated using bedtools genomeCoverageBed and converted to bigwig files using bedGraphToBigWig application from UCSC Genome Browser. Bigwig files were visualised using IGV. After alignment, number of reads on the genes were summarised using HTSeqcount (version 0.5.4; Ref. ${ }^{65}$ ). All downstream analysis was carried out in R (version 3.4.0). Differentially expressed genes between condition were determined using DESEq2 (Ref. ${ }^{66}$ ). P-values calculated by DESeq2 were subjected to multiple testing correction using Benjamini-Hochberg method. Adjusted $p$-value of 0.05 was used to select the differentially expressed genes. Principal Component Analysis (PCA) and hierarchical clustering of samples were done on the normalised read counts (rlog) computed using DESeq2. KClinducible genes were defined as genes in $\operatorname{Rad} 21^{+/+}$neurons with $\operatorname{adj} P<0.05$ and $\log 2$ fold change $>=1$ in $\mathrm{KCl} 1 \mathrm{~h}$ versus (vs) TTX or KCl6h vs TTX. As reference we used previously defined activity dependent genes ${ }^{19}$. Constitutive genes were defined as expressed genes in $\operatorname{Rad} 21^{+/+}$neurons with adj. $P>=0.05$ in $\mathrm{KCl} 1 \mathrm{~h}$ vs TTX and KCl6h vs TTX.

GO terms enriched among differentially expressed genes were identified using goseq $R$ package ${ }^{67}$ using all expressed genes in each comparison as background. GSEA was performed as described ${ }^{68}$ using GSEA Desktop v3.0 (http://www.broadinstitute.org/gsea). 'Wald statistics' from DESeq2 differential expression analysis were used to rank the genes for GSEA. The gene set collections C2 (curated; KEGG 186 gene sets) and C5 (GO ontologies; 5917 gene sets) were obtained from Molecular Signature Database (MSigDB version 6.1; Broad Institute, http://www.broadinstitute.org/gsea/msigdb).

Chromatin immunoprecipitation. ChIP was performed as described ${ }^{22,69}$ with minor modifications. Briefly, cells were cross-linked for 10 minutes at room temperature with rotation using $1 \%$ formaldehyde in cross-linking buffer $(0.1 \mathrm{M} \mathrm{NaCl}, 1 \mathrm{mM}$ EDTA, $0.5 \mathrm{mM}$ EGTA and $25 \mathrm{mM} \mathrm{HEPES-KOH}, \mathrm{pH}$ 8.0). The reaction was quenched using $125 \mathrm{mM}$ glycine for 5 minutes with rotation and the cells were washed three times using ice-cold PBS containing complete protease inhibitor cocktail tablets (Roche). Cells were resuspended in lysis buffer (1\% SDS, $50 \mathrm{mM}$ Tris-HCl pH 8.1, $10 \mathrm{mM}$ EDTA pH 8) with EDTA-free protease inhibitor cocktail and incubated for 30 minutes on ice. Cell lysates were then sonicated 20 times at $4^{\circ} \mathrm{C}$ (Bioruptor Plus, Diagenode, 30/30 cycles) and centrifuged at $14000 \mathrm{rpm}$ for 1 minute at $4{ }^{\circ} \mathrm{C}$ to remove cellular debris. $10 \%$ of total volume was taken as input. Input samples were reverse crosslinked overnight at $65^{\circ} \mathrm{C}$, then incubated for $1 \mathrm{~h}$ with $9 \mathrm{mM}$ EDTA pH 8, $3.6 \mathrm{mM}$ Tris- $\mathrm{HCl} \mathrm{pH} 6.8$ and $36 \mu \mathrm{g} / \mathrm{mL}$ proteinase $\mathrm{K}$ at $45^{\circ} \mathrm{C}$. Input chromatin purification was performed using phenol-chloroform at $4^{\circ} \mathrm{C}$. Total chromatin was pre-cleared for $1 \mathrm{~h}$ at $4^{\circ} \mathrm{C}$ with rotation using protein A sepharose beads (P9424, Merck). $3 \mu \mathrm{g}$ of antihistone H3 (Abcam, ab1791) and $5 \mu \mathrm{g}$ of anti-H3K27Ac (Active Motif, 39133) were added overnight at $4^{\circ} \mathrm{C}$ with rotation. $100 \mu \mathrm{L}$ of protein $\mathrm{A}$ sepharose beads were added to each IP for at least $4 \mathrm{~h}$ before being washed with low salt buffer $(150 \mathrm{mM} \mathrm{NaCl}, 2 \mathrm{mM}$ Tris pH 8.1, $0.1 \%$ SDS, $1 \%$ Triton X-100 and $2 \mathrm{mM}$ EDTA pH 8), high salt buffer $(500 \mathrm{mM} \mathrm{NaCl}, 20 \mathrm{mM}$ Tris $\mathrm{pH} 8.1,0.1 \%$ SDS, $1 \%$ Triton $\mathrm{X}-100$ and $2 \mathrm{mM}$ EDTA pH 8$)$, LiCl salt buffer $(0.25 \mathrm{mM}$ $\mathrm{LiCl}, 10 \mathrm{mM}$ Tris $\mathrm{pH} 8.1,1 \% \mathrm{NP}-40,1 \%$ sodium deoxycholate and $1 \mathrm{mM}$ EDTA pH 8 ) and Tris-EDTA buffer (10 mM Tris pH 8.1 and $1 \mathrm{mM}$ EDTA pH 8). Chelex-100 (Bio-Rad, catalog number \#1421253) was added to the samples, which were then boiled and incubated for $1 \mathrm{~h}$ at $55^{\circ} \mathrm{C}$ with $36 \mu \mathrm{g} / \mathrm{mL}$ proteinase $\mathrm{K}$ and boiled once again. Samples were centrifuged at $12000 \mathrm{rpm}$ for 1 minute and the beads washed once with nuclease-free water. The following PCR primers were used: Control region chr11: 71.177.622-71.177.792: forward, 5'- 
CATTCCAGGGCAACTCCACT-3', reverse, 5'-CAGGGGCTCCTGTACTACCT-3'; Fos enhancer 1 forward, 5'-TCCGGTAAGGGCATTGTAAG-3', reverse, 5'CAAAGCCAGACCCTCATGTT-3'; Fos enhancer forward, 5'-TGCAGCTCTGCTCCTACTGA3', reverse, 5'-GAGGAGCAAGACTCCCACAG-3'

3C Template Generation. Neuronal cultures were fixed in 1\% formaldehyde for 10 minutes (room temp) via the addition (1:10 vol/vol) of the following fixation solution: $50 \mathrm{mM}$ Hepes$\mathrm{KOH}$ (pH 7.5), $100 \mathrm{mM} \mathrm{NaCl}, 1 \mathrm{mM}$ EDTA, $0.5 \mathrm{mM}$ EGTA, 11\% Formaldehyde. Fixation was quenched via the addition of $2.5 \mathrm{M}$ glycine (1:20 vol/vol) and scraped into pellets. Each pellet was washed once with cold PBS, flash frozen, and stored at $-80^{\circ} \mathrm{C}$. For each condition, in situ $3 \mathrm{C}$ was performed on 2 replicates of 4-5 million cells as described ${ }^{25}$. Briefly, cells were thawed on ice and resuspended (gently) in $250 \mu \mathrm{L}$ of lysis buffer ( $10 \mathrm{mM}$ Tris- $\mathrm{HCl} \mathrm{pH} \mathrm{8.0,10} \mathrm{mM} \mathrm{NaCl,} \mathrm{0.2 \%} \mathrm{Igepal} \mathrm{CA630)} \mathrm{with} 50 \mu \mathrm{L}$ protease inhibitors (Sigma P8340). Cell suspension was incubated on ice for 15 minutes and pelleted. Pelleted nuclei were washed once in lysis buffer (resuspension and spin), then resuspended and incubated in $50 \mu \mathrm{L}$ of $0.5 \%$ SDS at $62^{\circ} \mathrm{C}$ for $10 \mathrm{~min}$. SDS was inactivated via the addition of $145 \mu \mathrm{L}$ $\mathrm{H}_{2} \mathrm{O}, 25 \mathrm{uL} 10 \%$ Triton X-100, and incubation at $37^{\circ} \mathrm{C}$ for $15 \mathrm{~min}$. Subsequently, chromatin was digested overnight at $37^{\circ} \mathrm{C}$ with the addition of $25 \mu \mathrm{L} 10 \mathrm{X}$ NEBuffer2 and $100 \mathrm{U}(5 \mu \mathrm{L})$ of HindIII (NEB, R0104S), followed by 20 min incubation at $62^{\circ} \mathrm{C}$ to inactivate the HindIII. Chromatin was re-ligated via the addition of $100 \mu \mathrm{L} 10 \%$ Triton X-100, $120 \mu \mathrm{L}$ NEB T4 DNA Ligation buffer (NEB B0202S), $12 \mu \mathrm{L} 10 \mathrm{mg} / \mathrm{mL}$ BSA, $718 \mu \mathrm{L} \mathrm{H} \mathrm{H}_{2} \mathrm{O}$, and $2000 \mathrm{U}(5 \mu \mathrm{L})$ of T4 DNA Ligase (NEB M0202S) and incubation at $16^{\circ} \mathrm{C}$ for 2 hours. Following ligation nuclei were pelleted, resuspended in $300 \mu \mathrm{L}$ of $10 \mathrm{mM}$ Tris- $\mathrm{HCl}(\mathrm{pH} 8.0), 0.5 \mathrm{M} \mathrm{NaCl}, 1 \%$ SDS, plus $25 \mu \mathrm{L}$ of $20 \mathrm{mg} / \mathrm{mL}$ proteinase $\mathrm{K}$ (NEB P8107), and incubated at $65^{\circ} \mathrm{C}$ for 4 hours at which point an additional $25 \mu \mathrm{L}$ of proteinase $\mathrm{K}$ was added and incubated overnight. $3 \mathrm{C}$ templates were isolated next day via RNaseA treatment, phenol-chloroform extraction, ethanol precipitation, and Amicon filtration (Millipore MFC5030BKS). Template size distribution and quantity were assessed with a $0.8 \%$ agarose gel.

5C Library Preparation. 5C primers which allow for the query of genome folding at ultrahigh resolution but on a reduced subset of the genome were designed according to the double-alternating design scheme ${ }^{27}$ using the My5C primer design software ${ }^{70}$ (http://my5c.umassmed.edu/my5Cprimers/5C.php) with universal "Emulsion" primer tails. Regions were designed to capture TAD structures immediately surrounding the genes of interest in published mouse cortex $\mathrm{HiC}$ data ${ }^{40} .5 \mathrm{C}$ reactions were carried out as previously described ${ }^{27}$. $600 \mathrm{ng}$ ( 200,000 genome copies) of 3C template for each replicate was mixed with 1 fmole of each $5 \mathrm{C}$ primer and $0.9 \mathrm{ug}$ of salmon sperm DNA in 1x NEB4 buffer, denatured at $95^{\circ} \mathrm{C}$ for $5 \mathrm{~min}$, then incubated at $55^{\circ} \mathrm{C}$ for 16 hours. Primers which had then annealed in adjacent positions were ligated through the addition of $10 \mathrm{U}(20 \mu \mathrm{L})$ Taq ligase (NEB M0208L) and incubation at $55^{\circ} \mathrm{C}$ for 1 hour then $75^{\circ} \mathrm{C}$ for $10 \mathrm{~min}$. Successfully ligated primer-primer pairs were amplified using primers designed to the universal tails (FOR $=$ CCTCTC TATGGGCAGTCGGTGAT, REV = CTGCCCCGGGTTCCTCATTCTCT) across 30 PCR cycles using Phusion High-Fidelity Polymerase. Presence of a single PCR product at 100 bp was confirmed via agarose gel, then residual DNA $<100$ bp was removed through AmpureXP bead cleanup at a ratio of $2: 1$ beads:DNA (vol/vol). $100 \mathrm{ng}$ of the resulting $5 \mathrm{C}$ product was prepared for sequencing on the Illumina NextSeq 500 using the NEBNext Ultra DNA Library Prep Kit (NEB E7370) following the manufacturer's instructions with the 
following parameter selections: during size selection, $70 \mu \mathrm{L}$ of AMPure beads was added at the first step and 25 at the second step; linkered fragments were amplified using 8 PCR cycles. A single band at 220 bp in each final library was confirmed using an Agilent DNA 1000 Bioanalyzer chip, and library concentration was determined using the KAPA Illumina Library Quantification Kit (\#KK4835). Finally, libraries were evenly pooled and sequenced on the Illumina NextSeq 500 using 37 bp paired-end reads to read depths of between 11 and 30 million reads per replicate.

5C Interaction Analysis. 5C analysis steps were performed as described ${ }^{27}$. Briefly, pairedend reads were aligned to the $5 \mathrm{C}$ primer pseudo-genome using Bowtie, allowing only reads with one unique alignment to pass filtering. Only reads for which one paired end mapped to a forward/left-forward primer and the other end mapped to a reverse/left-reverse primer were tallied as true counts. Primer-primer pairs with outlier count totals, resulting primarily from PCR bias, were identified as those with a count at least 8-fold higher (100-fold for the lowerquality Arc region) than the median count of the $5 \times 5$ subset of the counts matrix centered at the primer-primer pair in question; outlier counts were removed.

Primer-primer pair counts were then converted to fragment-fragment interaction counts by averaging the primer-primer counts that mapped to each fragment-fragment pair (max of 2 if both a forward/left-forward and a reverse/left-reverse primer were able to be designed to both fragments and were not trimmed during outlier removal). We then divided our 5C regions into adjacent $4 \mathrm{~kb}$ bins and computed the relative interaction frequency of two bins (i,j) by summing the counts of all fragment-fragment interactions for which the coordinates of one of the constituent fragments overlapped (at least partially) a $12 \mathrm{~kb}$ window surrounding the center of the $4 \mathrm{~kb}^{\text {th }}$ bin and the other constituent fragment overlapped the $12 \mathrm{~kb}$ window surrounding the center if the $\mathrm{j}^{\text {th }}$ bin. Binned count matrices were then matrix balanced using the ICE algorithm ${ }^{71,72}$ and quantile normalized across all 8 replicates ( 2 per condition) as previously described ${ }^{27}$, at which point we considered each entry $(\mathrm{i}, \mathrm{j})$ to represent the 'Relative Interaction Frequency' of the $4 \mathrm{~kb}$ bins i and j. Finally, the background contact domain 'expected' signal was calculated using the donut background mode ${ }^{73}$ and used to normalize the relative interaction frequency data for the background interaction frequency present at each bin-bin pair. The resulting background-normalized interaction frequency ("observed over expected") counts were fit with a logistic distribution from which p-values were computed for each bin-bin pair and converted into 'Background-corrected Interaction Scores' (interaction score $=-10^{*} \log _{2}(\mathrm{p}$-value)), which have previously shown to be informatively comparable across replicates and conditions ${ }^{25}$.

Identification of neuronal enhancers. H3K27Ac ChIPSeq and corresponding input datasets $^{22}$ were from NCBI GEO using accession GSE60192. The sra files were converted to fastq using sratoolkit and aligned to mouse genome $\mathrm{mm} 9$ using bowtie verion 0.12 .8 with default parametes ${ }^{74}$. Sequencing reads aligned to multiple positions in the genome were discarded. Duplicate reads were identified using Picard tools v 1.90 and removed from the downstream analysis. H3K27Ac peaks were identified using macs2 with "--broad" parameters ${ }^{75}$. Gene coordinates were obtained from Ensembl using "biomaRt" R package ${ }^{76}$ and enhancers were assigned to nearest genes using "nearest" function from 'GenomicRanges” R package ${ }^{77}$. 
Immunocytochemistry. Neurons plated on coverslips were fixed with warmed to $37^{\circ} \mathrm{C}$ PBS containing $4 \%$ paraformaldehyde and $4 \%$ sucrose for $10 \mathrm{~min}$ at room temperature. Neurons were then permeabilized with $0.3 \%$ Triton X-100 for 10 min and treated with blocking solution (10\% normal goat serum, $0.1 \%$ Triton X-100 in PBS) for one hour. Primary and secondary antibodies were diluted in $0.1 \%$ Triton $X-100,2 \%$ normal goat serum in PBS. Appropriate primary antibodies were incubated with samples for two hours at room temperature or overnight at $4^{\circ} \mathrm{C}$. Primary antibodies used were specific to RAD21 (1:500; rabbit polyclonal ab154769, Abcam), MAP2 (1:5000; chicken polyclonal ab611203, Abcam), GAD67 (1:500; mouse monoclonal MAB5406, Millipore), HA (1:1000; mouse monoclonal MMS-101R, Covance), GFAP (1:500; rabbit polyclonal Z0334, Dako) or IBA1 (1:250; rabbit polyclonal 019-19741, Wako). Secondary antibodies were incubated for $1 \mathrm{~h}$ at room temperature. Goat anti-rabbit IgG $(\mathrm{H}+\mathrm{L})$ Alexa Fluor 647 (A-21244, ThermoFisher), Goat anti-Rabbit IgG $(\mathrm{H}+\mathrm{L})$ Alexa Fluor 568 (A-11011, ThermoFisher), goat anti-mouse lgG $(\mathrm{H}+\mathrm{L})$ Alexa Fluor $488(\mathrm{~A}-11001$, ThermoFisher), goat anti-chicken $\lg \mathrm{Y}(\mathrm{H}+\mathrm{L})$ Alexa Fluor 568 (ab175711, Abcam) conjugates were used at a 1:500 dilution. Cells were mounted in Vectashield medium containing DAPI (Vector Labs).

Embryonic brains were fixed for 4 hours in $4 \%$ paraformaldehyde in PBS, washed in PBS, transferred to $15 \%$ sucrose in PBS for cryopreservation, embedded in OCT and stored at $80^{\circ} \mathrm{C}$ until use. Coronal sections of $10 \mu \mathrm{m}$ were cut with a Leica cryostat and mounted on glass slides. The sections were washed two times for ten minutes in PBS, blocked with $0.3 \%$ TritonX-100, 5\% normal goat serum in PBS, at room temperature and incubated overnight with the primary antibody solution. Sections were then washed three times for ten minutes each in PBS and were incubated for one hour in the dark with the secondary antibody solution. The primary antibodies were specific to RAD21 (1:500; rabbit polyclonal ab154769, Abcam), anti-gamma-H2AX (1:3000; rabbit polyclonal A300-081A, Bethyl Laboratories), Cleaved Caspase-3 (Asp175) (1:400; rabbit polyclonal 9661, Cell signalling), TBR1 (1:1000; rabbit polyclonal ab31940, Abcam), CTIP2 (1:500; rat monoclonal [25B6] ab18465, Abcam), CUX-1 (1:400; rabbit polyclonal sc-13024, Santa Cruz) and anti phospho-histone H3 (Ser10) Alexa Fluor 647 conjugate (1:50; rabbit polyclonal 9716 , Cell signalling). The secondary antibodies used are described in the previous section. Sections were mounted with Vectashield medium containing DAPI.

Confocal Image analysis and quantification. For quantification analysis of RAD21 negative neurons and inhibitory neurons (GAD67+) images $(1024 \times 1024$ pixels) were acquired using TCS SP5 confocal microscope (Leica Microsystems), using a HCX PL APO CS 40x/1.25 lens at zoom factor 1 (373 nm/pixel). Images were acquired with identical settings for laser power, detector gain, and amplifier offset, with pinhole diameters set for 1 airy unit. DAPI-identified nuclei that colocalized with the GAD67 signal, or without RAD21 signal were counted as inhibitory or RAD21 negative neurons, respectively; and were quantified using a processing pipeline developed in CellProfiler (version 2.2, Broad Institute, Harvard, Cambridge, MA, USA, www.cellprofiler.org). For astrocytes (GFAP+) and microglia (IBA1+) quantification in dissociated cortical neuronal cultures, the entire coverslips were imaged using a IX70 Olympus microscope equipped with a 4x 0.1 NA Plan-Neofluar lens $(1.60 \mu \mathrm{m} / \mathrm{pixel})$ and the number of astrocytes and microglia were counted. The analysis and quantification of different cell types were done for three different experiments, each experiment containing at least two different samples of each genotype. 
For Sholl analysis of dissociated cortical neurons, samples were imaged using a TCS SP8 confocal microscope, a HC PL APO CS2 40x/1.30 lens at zoom factor 0.75 with a resolution of $2048 \times 2048$ pixel ( $189 \mathrm{~nm} / \mathrm{pixel}, 0.5 \mu \mathrm{m} / \mathrm{stack}$ ). Images were acquired with identical settings for laser power, detector gain, and amplifier offset, with pinhole diameters set for 1 airy unit. Approximately 10 neurons were imaged per sample and at least two different samples per genotype in each experiment; each experiment was performed three times. GFP + neurons were traced using the FilamentTracer package in Imaris software (Bitplane AG). Statistical significance was assessed using a repeat measures ANOVA with a Bonferroni Post Test (Prism-GraphPad Software).

\section{Supplementary references}

61 Tachibana-Konwalski, K. et al. Rec8-containing cohesin maintains bivalents without turnover during the growing phase of mouse oocytes. Genes Dev 24, 2505-16 (2010).

62 Cuartero, S. et al. Control of inducible gene expression links cohesin to hematopoietic progenitor self-renewal and differentiation. Nat. Immunol. 19, 932-941 (2018).

63 Beaudoin, G. M. et al. Culturing pyramidal neurons from the early postnatal mouse hippocampus and cortex. Nat. Protoc. 7, 1741-54 (2012).

64 Kim D, Pertea G, Trapnell C, Pimentel H, Kelley R, Salzberg SL. TopHat2: accurate alignment of transcriptomes in the presence of insertions, deletions and gene fusions. Genome Biol. 14(4): R36 (2013).

65 Anders S, Pyl PT, Huber W. HTSeq--a Python framework to work with high-throughput sequencing data. Bioinformatics 31: 166-9 (2015). doi: 10.1093/bioinformatics/btu638.

66 Love, M. I., Huber, W. \& Anders, S. Moderated estimation of fold change and dispersion for RNA-seq data with DESeq2. Genome Biol. 15, 550 (2014).

67 Young, M. D., Wakefield, M. J., Smyth, G. K. \& Oshlack, A. Gene ontology analysis for RNA-seq: accounting for selection bias. Genome Biol. 11, R14 (2010).

68 Subramanian, A. et al. Gene set enrichment analysis: a knowledge-based approach for interpreting genome-wide expression profiles. Proc Natl Acad Sci U A 102, 15545-50 (2005)

69 Nelson JD, Denisenko O, Bomsztyk K. Protocol for the fast chromatin immunoprecipitation (ChIP) method. Nat Protoc. 1, 179-85 (2006). doi: 10.1038/nprot.2006.27.

70 Lajoie, B. R., van Berkum, N. L., Sanyal, A. \& Dekker, J. My5C: web tools for chromosome conformation capture studies. Nat. Methods 6, 690-691 (2009).

71 Imakaev, M. et al. Iterative correction of $\mathrm{Hi}-\mathrm{C}$ data reveals hallmarks of chromosome organization. Nat. Methods 9, 999-1003 (2012).

72 Gilgenast, T. G. \& Phillips-Cremins, J. E. Systematic evaluation of statistical methods for identifying looping interactions in 5C data. Cell Syst. 8, 197-211 e113 (2019)

$73 \mathrm{Su}, \mathrm{Y}$. et al. Neuronal activity modifies the chromatin accessibility landscape in the adult brain. Nat. Neurosci. 20, 476-483 (2017).

74 Langmead B, Trapnell C, Pop M, Salzberg SL. Ultrafast and memory-efficient alignment of short DNA sequences to the human genome. Genome Biol. 10(3): R25 (2009). doi: 10.1186/gb-2009-10-3-r25.

75 Zhang Y. et al. Model-based analysis of ChIP-Seq (MACS). Genome Biol. 9: R137 (2008). doi: 10.1186/gb-2008-9-9-r137 
76 Durinck S, Spellman PT, Birney E, Huber W. Mapping identifiers for the integration of genomic datasets with the R/Bioconductor package biomaRt. Nat Protoc. 4: 1184-91. doi: 10.1038/nprot.2009.97 (2009).

77 Lawrence M, Huber W, Pagès H, Aboyoun P, Carlson M, Gentleman R, Morgan MT, Carey VJ. Software for computing and annotating genomic ranges. PLoS Comput Biol. ;9(8):e1003118. (2013). doi: 10.1371/journal.pcbi.1003118

78 Schambra U. B., Lauder J. M., Silver J. Atlas of the prenatal mouse brain. Academic Press (1992)

\section{Supplementary Figures}
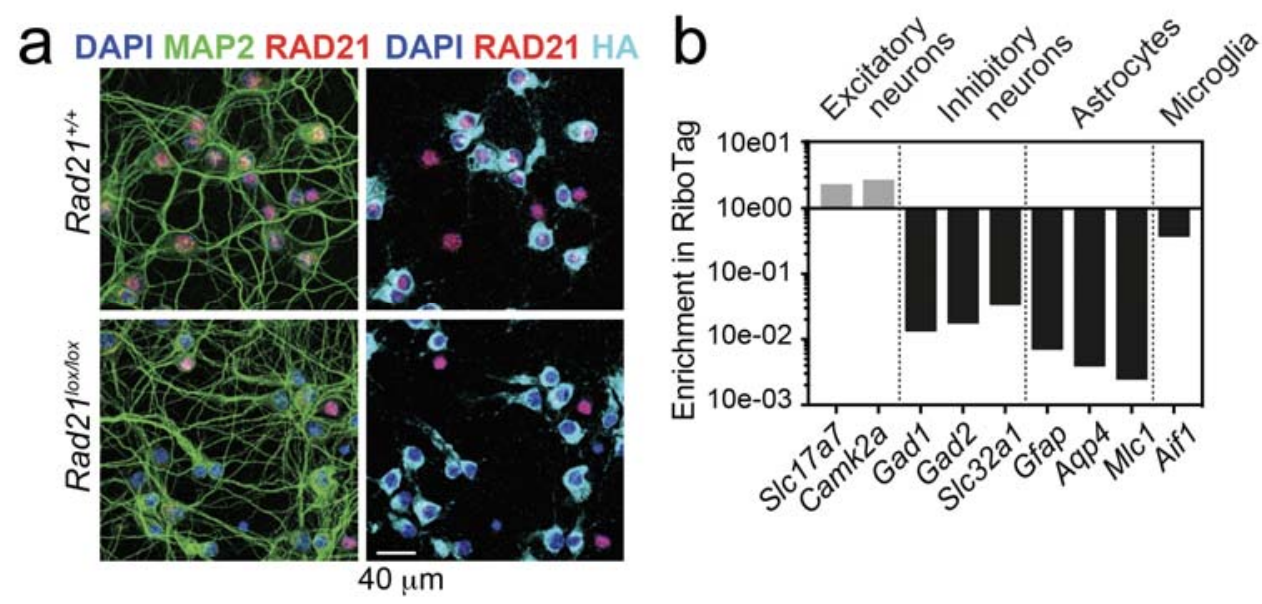

\section{Supplementary Figure 1. RiboTag validation.}

a) $\mathrm{Nex}^{\mathrm{Cre}}$-dependent Rpl22-HA (RiboTag) expression is restricted to RAD21-negative cells in Rad2 $1^{\text {lox/lox }} \mathrm{Nex}^{\mathrm{Cre}}$ neurons. Immunofluorescence staining for RAD21, the pan-neuronal marker MAP2 and HA (RiboTag) in explant culture. DAPI marks nuclei. Scale bar $=40 \mu \mathrm{m}$.

b) $\mathrm{Nex}{ }^{\mathrm{Cre}}$ RiboTag captures excitatory neuron-specific transcripts such as S/c17a7 and Camk2a and depletes cell type-specific transcripts expressed in inhibitory neurons (Gad1, Gad2, Slc32a1), astrocytes (Gfap, Aqp4, Mlc1), and microglia (Aif). Transcript enrichment (or depletion) was calculated using the normalized counts from $\mathrm{Nex}{ }^{\mathrm{Cre}}$ RiboTag versus standard RNA-seq in Rad $21^{+/+} \mathrm{Nex}$ Cre neurons. 
bioRxiv preprint doi: https://doi.org/10.1101/2021.02.24.432639; this version posted February 24, 2021. The copyright holder for this preprint (which was not certified by peer review) is the author/funder. All rights reserved. No reuse allowed without permission.

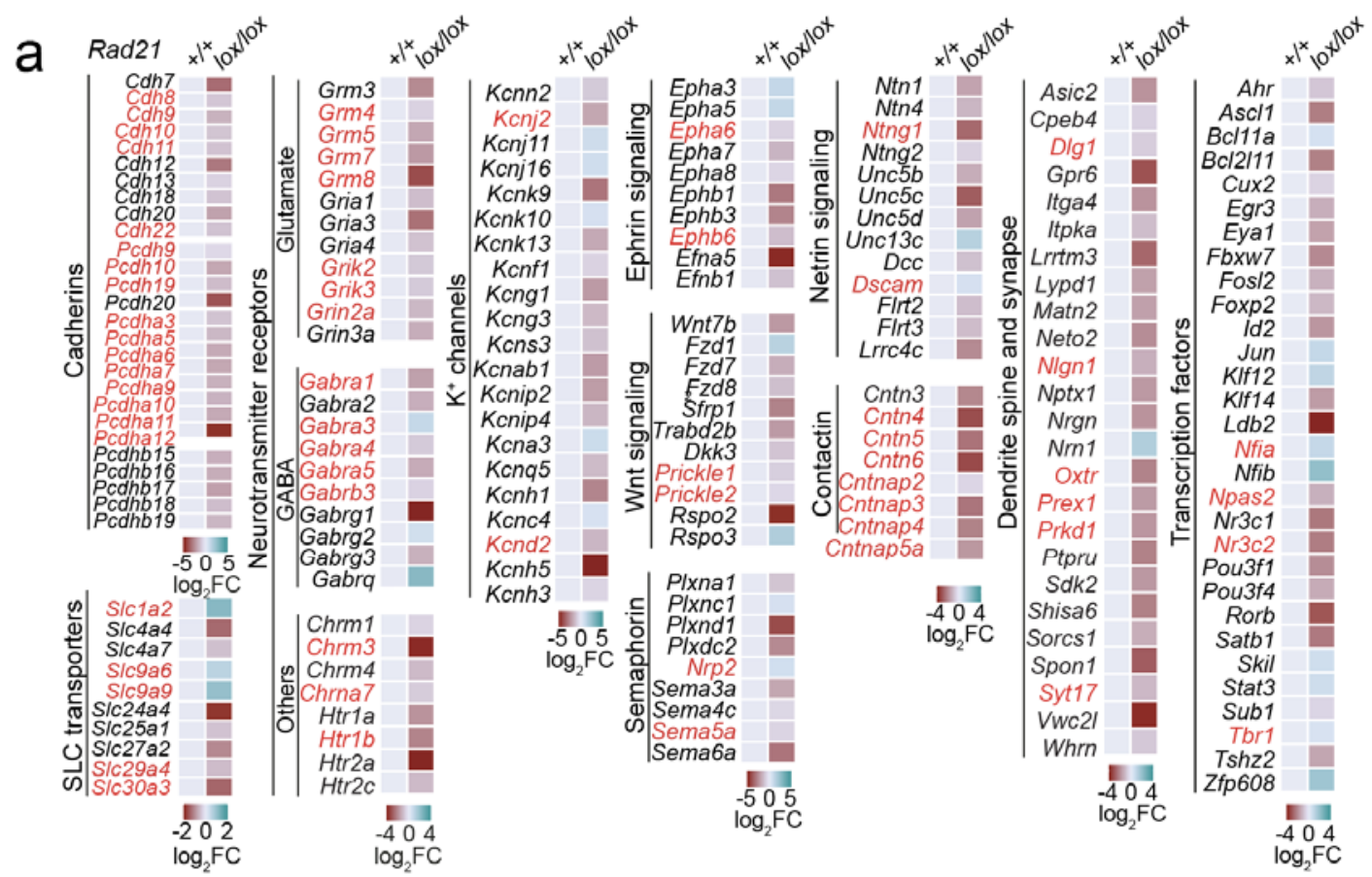

b (i) KEGG pathways $(q<0.05)$
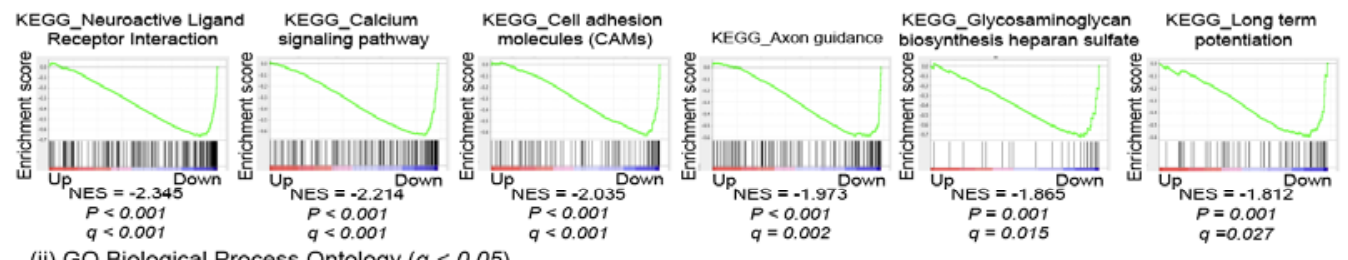

(ii) GO Biological Process Ontology $(q<0.05)$
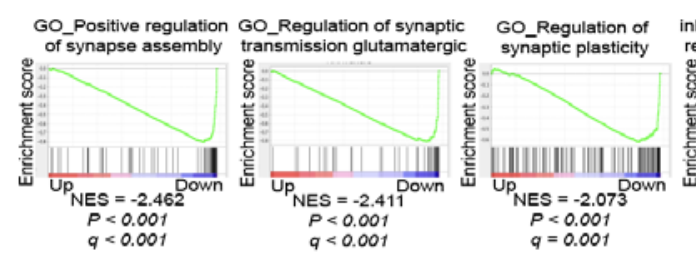

GO_Adenylate cyclase

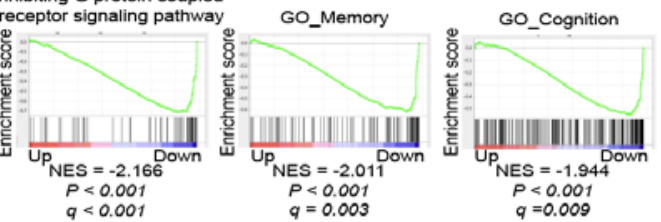

(iii) GO Molecular Function Ontology $(q<0.05)$
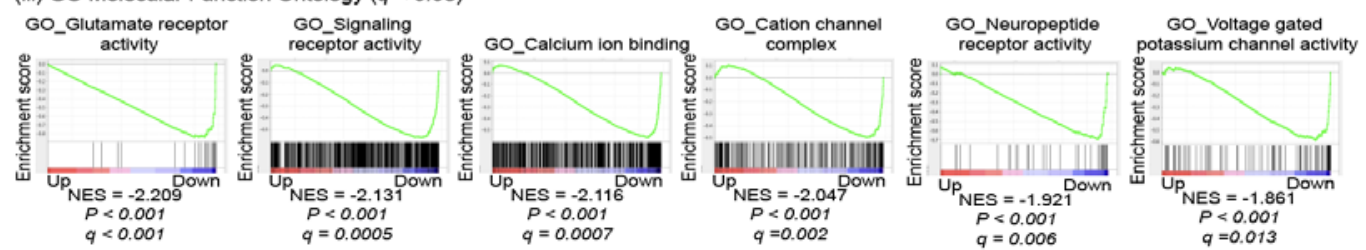

(iv) GO Cellular Component Ontology $(q<0.05)$

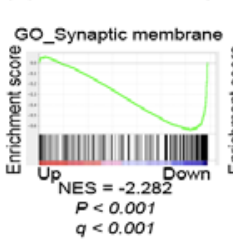

GO_Postsynaptic
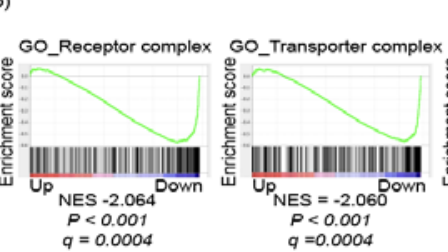

Go_lonotropic glutamate
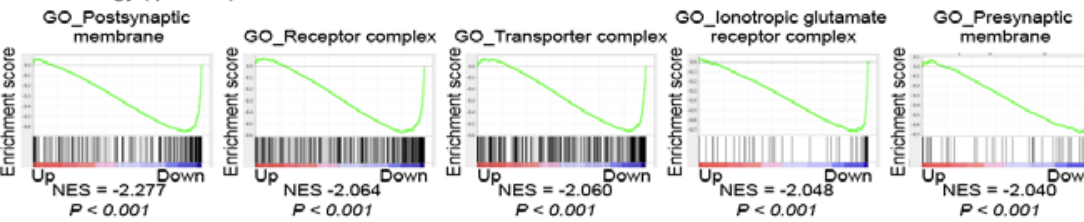

$q=0.0004$

$q=0.0004$

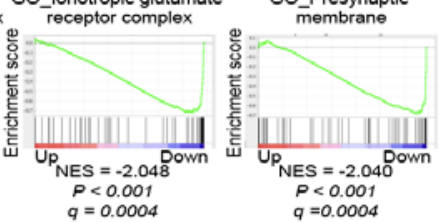

C
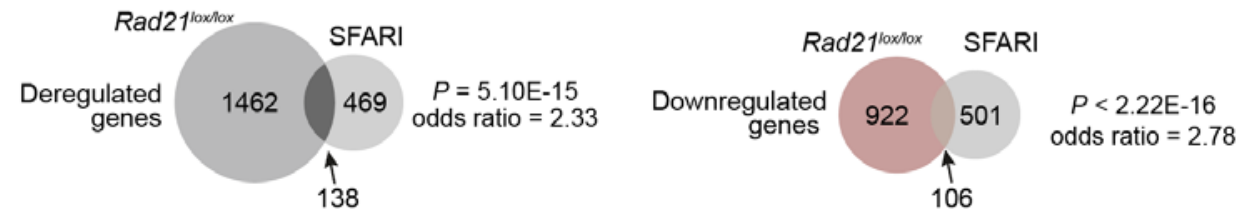


\section{Supplementary Figure 2. Gene expression in $\mathrm{Rad}_{21}^{\mathrm{lox} / \mathrm{lox}} \mathrm{Nex}{ }^{\mathrm{Cre}}$ neurons}

a) Examples of deregulated genes in $\mathrm{Rad} 21^{\mathrm{lox} / \mathrm{lox}} \mathrm{Ne} x^{\mathrm{Cre}}$ neurons. Genes associated with autism spectrum disorders are highlighted in red.

d) GSEA for downregulated genes in $\mathrm{Nex}^{\mathrm{Cre} /+} \mathrm{Rad} 21^{10 x / 10 x}$ neurons using gene sets derived from (i) KEGG pathway database, (ii) GO Biological Process Ontology, (iii) GO Molecular Function Ontology, (iv) GO Cellular Component Ontology in the Molecular Signatures Database (MSigDB).

c) Overlap between human genes associated with autism spectrum disorders from the SFARI database and differentially expressed genes (left), downregulated genes (middle) and upregulated genes (right) in $\mathrm{Rad} 21^{\text {lox/lox }} \mathrm{Nex}{ }^{\mathrm{Cre}}$ cortical neurons. 
a

\begin{tabular}{|c|c|c|c|}
\hline \multicolumn{4}{|c|}{$\operatorname{Rad} 21^{+/ 10 x} \times \operatorname{Rad} 21^{+1 / 0 x} \mathrm{Nex}^{\mathrm{Cre}} \mathrm{cross}$} \\
\hline & $\operatorname{Rad}_{21}{ }^{+/ 4}$ & $\operatorname{Rad} 21^{+/ 10 x}$ & Rad21 10x/10x \\
\hline Expected & 25.0 & 50.0 & 25.0 \\
\hline E18.5 & 23.8 & 52.4 & 23.8 \\
\hline $\mathrm{PO}$ & 31.1 & 55.6 & 13.3 \\
\hline $\mathrm{P} 7$ & 35.7 & 57.1 & 7.1 \\
\hline P14 & 35.7 & 64.3 & 0 \\
\hline P21 & 37.0 & 63.0 & 0 \\
\hline
\end{tabular}

C
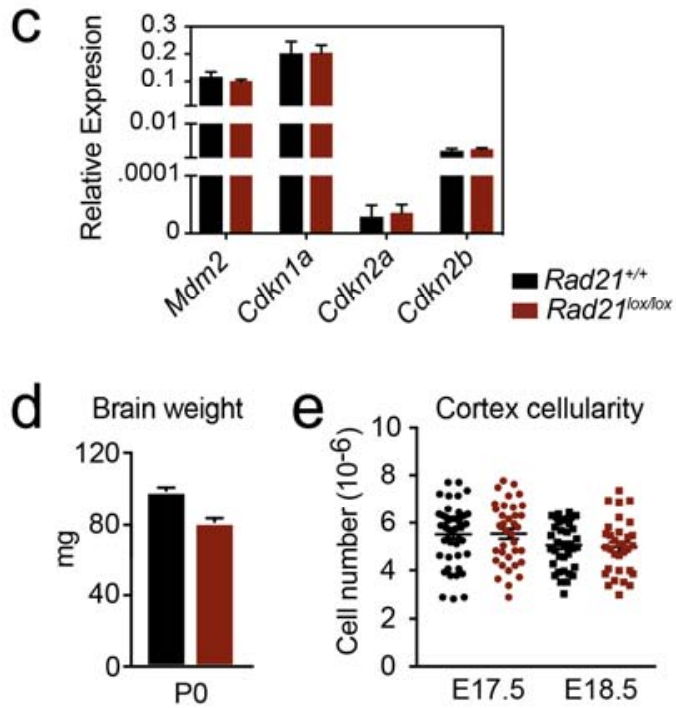

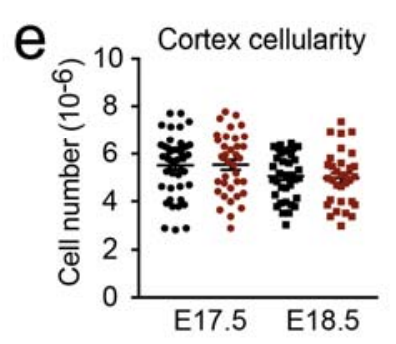

\section{Supplementary Figure 3. Impact of cohesin loss in immature post-mitotic neurons in} vivo.

a) Expected Mendelian ratios and observed percentages of live $\mathrm{Rad} 21^{1++} \mathrm{Nex}{ }^{\mathrm{Cre}}, \mathrm{Rad} 21^{10 \mathrm{x}+}$ $\mathrm{Nex}{ }^{\mathrm{Cre}}, \mathrm{Rad} 21^{\text {loxlox }} \mathrm{Nex}^{\mathrm{Cre}}$ mice at the indicated developmental stages, $\mathrm{n}=217$.

b) Immunofluorescence analysis shows neither the apoptosis marker activated caspase 3 (CC3) nor the DNA damage marker $\mathrm{HH}_{2} \mathrm{AX}$ in E16.5 (top) and E18.5 Rad2 $1^{\text {loxlox }} \mathrm{Nex}$ Cre (bottom, white lines demarcate the cortex). Wild type E16.5 thymi are shown as positive controls for $\mathrm{CC} 3$ and $\gamma \mathrm{H} 2 \mathrm{AX}$. Two biological replicates. Scale bar $=100 \mu \mathrm{m}$.

Photomicrographs of coronal brain sections at gestational age E16 modified from the Atlas of the prenatal mouse brain ${ }^{78}$ are shown for orientation.

c) Quantitative RT-PCR analysis of gene expression in Rad $21^{+/ t} \mathrm{Nex}$ Cre and Rad2 $1^{\text {loxlox }}$ $\mathrm{Nex}{ }^{\mathrm{Cre}}$ E17.5/18.5 cortical explant cultures $10 \mathrm{~d}$ after plating. Hprt and $U b c$ were used for normalization. Mean \pm SEM of 3 cultures per genotype.

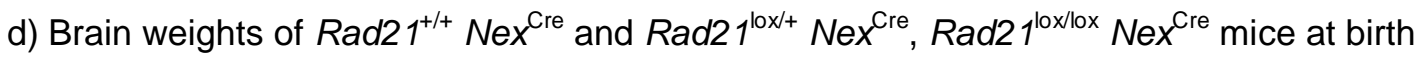
(P0). Mean \pm SEM of between 3 and 13 mice per genotype.

e) Embryonic cortices from wild-type and Rad2 $1^{10 \times 10 x} \mathrm{Nex}$ Cre mice were dissected at E17.5 and E18.5 and dissociated. Cortical cell numbers were determined by counting in Neubauer chambers. Each symbol denotes an independent experiment. Mean \pm SEM are also shown. 
a

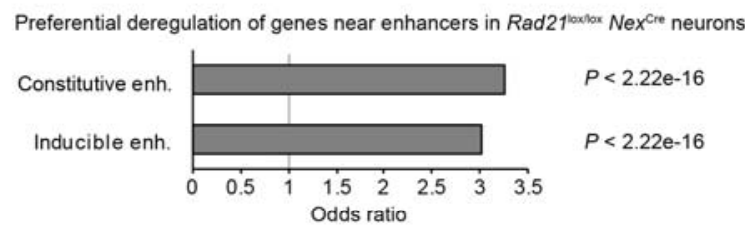

b

Enrichment of activity-dependent genes near neuronal enhancers

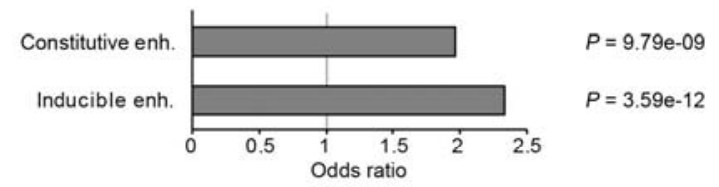
C Class Number CTCF peak No CTCF peak All genes $\quad 16885 \quad 2229(13.2 \%) \quad 14656(86.8 \%)$ Activity-dep. genes $\quad 305 \quad 36(11.8 \%) \quad 269(88.2 \%)$ Constitutive genes $\quad 9864 \quad 1290(13.1 \%) \quad 8574(86.9 \%)$ $\begin{array}{llll}\text { Enhancers } & 9862 & 975(9.9 \%) & 8887(90.1 \%)\end{array}$

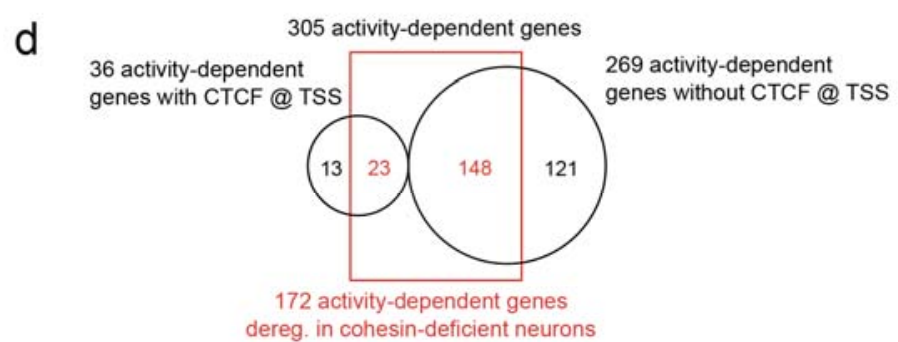

e

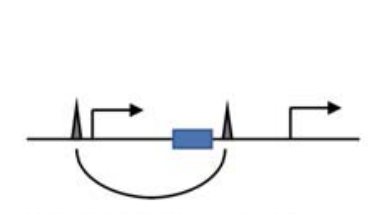

Direct CTCF-based E-P loop

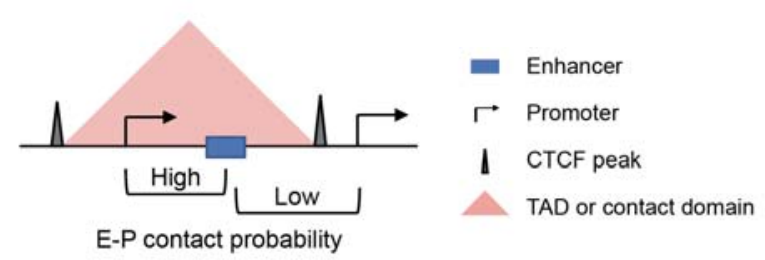

\section{Supplementary Figure 4. Enhancer proximity and CTCF occupancy of deregulated genes in $\operatorname{Rad} 21^{\text {lox/lox }} \mathrm{Nex}^{\mathrm{Cre}}$ neurons}

a) Preferential deregulation in $\mathrm{Rad} 21^{10 x / l o x} \mathrm{Nex}{ }^{\mathrm{Cre}}$ neurons of genes near constitutive and $\mathrm{KCl}$ inducible neuronal enhancers ${ }^{20}$. Based on 3 RiboTag RNA-seq replicates per genotype.

b) Enrichment of inducible activity-dependent genes near constitutive and $\mathrm{KCl}$-inducible neuronal enhancers ${ }^{20}$.

c) CTCF binding at neuronal genes and enhancers. All genes: all expressed genes in total RNA-seq; Activity-dependent genes: Previously defined activity-dependent genes (Kim et al., 2010) that are inducible by $\mathrm{KCl}$ in our experiments ( $\mathrm{KCl}$ minus TTX adj. $P<0.05$ ); Constitutive genes: Expressed genes that are not inducible by $\mathrm{KCl}$ in our experiments $(\mathrm{KCl}$ minus TTX adj. $P>0.05$ ); Enhancers: Previously defined forebrain enhancers ${ }^{50}$; CTCF binding: Previously defined CTCF binding peaks ${ }^{40}$ within $1 \mathrm{~kb}$ of TSS or enhancer. 
d) Only a minority of activity-dependent gene promoters are directly bound by CTCF, and most activity-dependent genes that lack CTCF promoter binding are nevertheless deregulated in cohesin-deficient neurons.

e) Models of gene regulation by direct (left) versus domain-wide chromatin contacts (right). CD: contact domain.

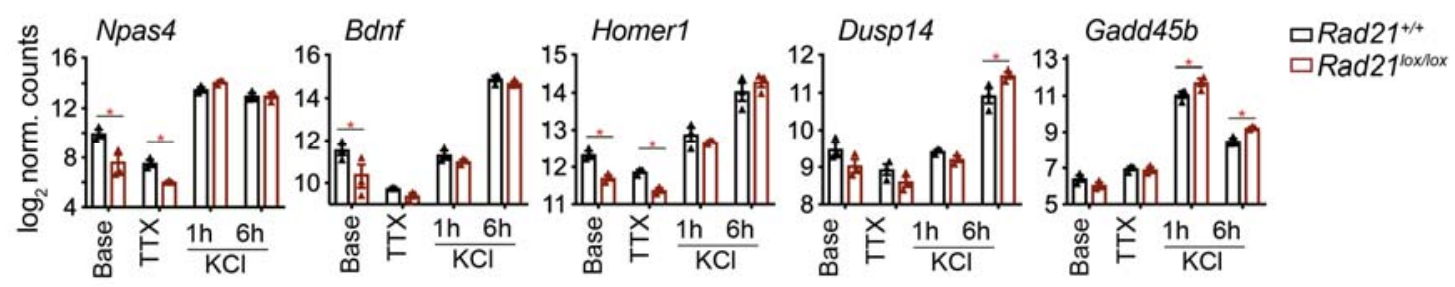

\section{Supplementary Figure 5. Inducible gene expression in cohesin-deficient neurons}

Examples of activity-dependent gene expression at baseline, after TTX/D-AP5 (TTX), and $\mathrm{KCl}$-stimulation. Mean log2-transformed counts from 3 biological replicates ( ${ }^{*}$ adj. $P<0.05$ ).

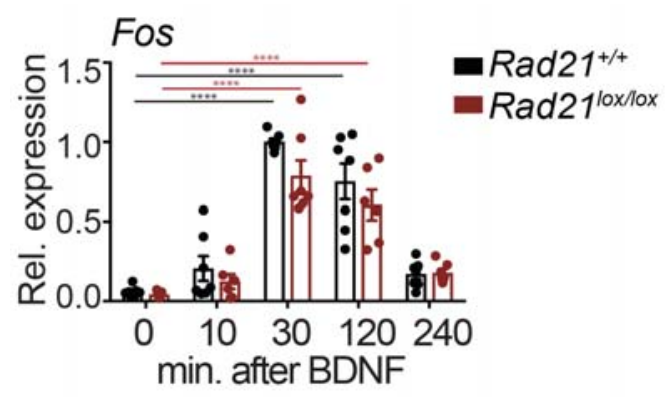

Supplementary Figure 6. Fos remains inducible by BDNF in cohesin-deficient neurons

Expression of Fos mRNA at baseline and at the indicated time after BDNF stimulation. Data points represent biological RT-PCR replicates. $P$-values refer to induction relative to $0 \mathrm{~min}$. ${ }^{* * *} P<0.001$. 

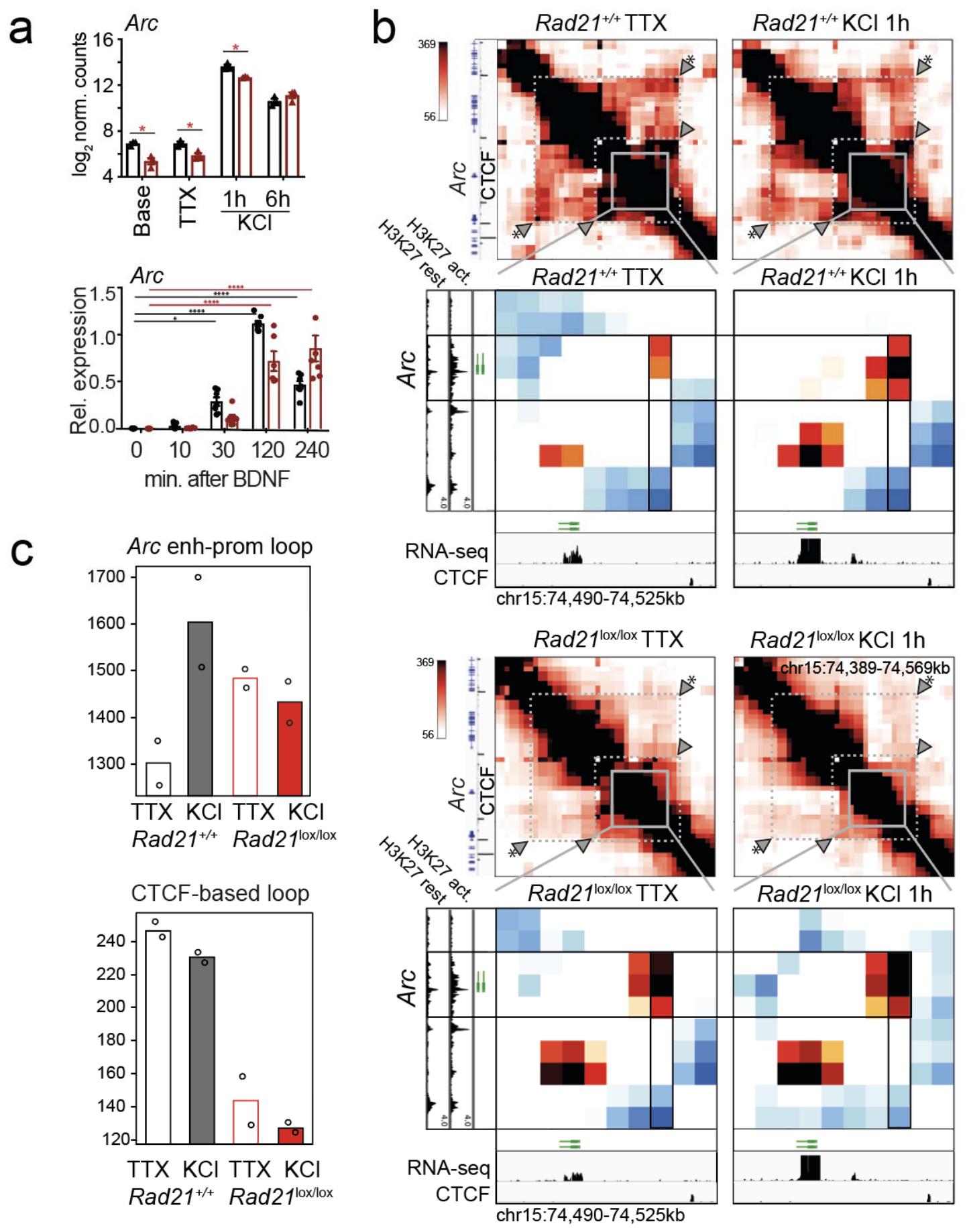

\section{Supplementary Figure 7. Contacts between the Arc promoter and an inducible enhancer in wild-type and cohesin-deficient neurons.}

a) Expression of Arc mRNA at baseline, after TTX/D-AP5 (TTX), and KCl-stimulation (top, mean log2-transformed counts from 3 biological RNA-seq replicates, ${ }^{*}$ adj. $P<0.05$ ) and at 
the indicated time after BDNF stimulation (bottom, data points represent biological RT-PCR replicates). $P$-values refer to induction relative to $0 \mathrm{~min}$. ${ }^{*} P<0.05,{ }^{* * *} P<0.001$.

b) Interaction score heatmaps of the $\sim 40 \mathrm{~kb}$ region immediately surrounding Arc obtained by $5 \mathrm{C}$ for resting (TTX) and $1 \mathrm{~h} \mathrm{KCl-activated} \mathrm{wild-type} \mathrm{(top)} \mathrm{and} \mathrm{Rad21}{ }^{\text {lox/lox }} \mathrm{Nex}$ Cre neurons (bottom). Black frames highlight interaction between the Arc gene (y-axis) and a nearby downstream enhancer (x-axis). Previously published CTCF-ChIP-seq is shown ${ }^{40}$. H3K27ac ChIP-seq in inactive (TTX-treated) and activated neurons is shown to annotate enhancer regions $^{25}$. Two independent biological replicates are shown in Supplementary Fig. 8c,d.

c) Quantification of 5C data. Arc enhancer-promoter loop (top). A CTCF-based loop that braces the Arc locus (arrowhead marked with * in panel b) is quantified for comparison (bottom). 


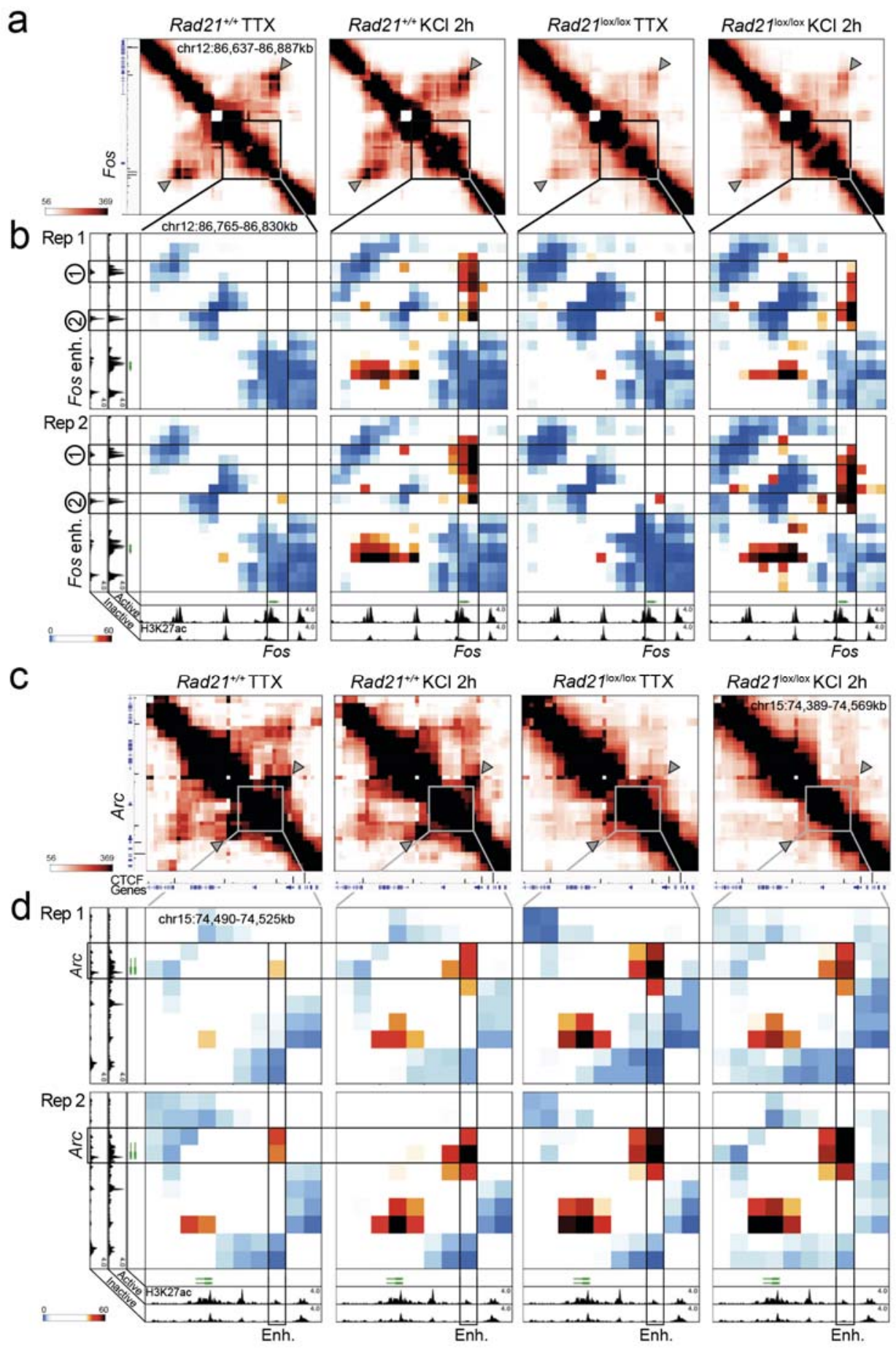

\section{Supplementary Figure 8. Replicate 5C experiments.}

a) Top: Interaction frequency zoom-in heatmaps of $250 \mathrm{~kb}$ region surrounding the Fos gene. Dashed lines and arrow heads mark major CTCF binding sites at the boundaries of the domain that contains Fos. Note the weakening of these contacts in Rad2 ${ }^{\text {loxlox }} \mathrm{Nex}{ }^{\mathrm{Cre}}$ neurons. Bottom: Interaction score heatmaps of the $65 \mathrm{~kb}$ region immediately surrounding the Fos gene. Black frames highlight interactions between the Fos gene and upstream 
enhancers 1 and 2. H3K27ac ChIP-seq data ${ }^{25}$ from Bicuculline-treated (active) and TTXtreated (inactive) neurons annotate enhancer regions. Two independent biological replicates are shown.

b) Top: Interaction frequency zoom-in heatmaps of $\sim 200 \mathrm{~kb}$ region surrounding the Arc gene. Dashed lines and arrow heads mark major CTCF binding sites at the boundaries of domains that contain the Arc locus. Note the weakening of these contacts in Rad21 lox/lox $\mathrm{Nex}{ }^{\mathrm{Cre}}$ neurons. Bottom: Interaction score heatmaps of the $\sim 40 \mathrm{~kb}$ region immediately surrounding the Arc gene. Black frames highlight interaction between the Arc gene (y-axis) and a nearby downstream enhancer (x-axis). H3K27ac ChIP-seq data ${ }^{25}$ from Bicucullinetreated (active) and TTX-treated (inactive) neurons annotate enhancer regions. Two independent biological replicates are shown. 